\title{
... einem ersamen Rath verehrt. Über Widmungen der Musikalien an mährische Städte ca. 1560-1620'1
}

\section{... einem ersamen Rath verehrt. About dedications of musical compostions to Moravian cities ca. 1560-1620}

\author{
Hana Studeničová / hana.studenicova@savba.sk \\ Institute of Musicology, Slovak academy of sciences, Bratislava, SK
}

\begin{abstract}
The musical sources of choirs and parish churches in Moravia region from the period 1550-1620 were not preserved with a few exceptions. The same applies to music inventories, which are not available for all cities. Because of this basic information about the performing practice of parish churches is often provided by books of municipal and church accounts, books with city correspondence and other documents. Sending of musical compositions, other philosophical and historiographical texts or glorious poems to city councils, but also to abbots or bishops, was a typical phenomenon of the early modern period. In the case of four Moravian royal towns (Brno, Znojmo, Jihlava, Olomouc), the surprising is frequency of records about remunerations provided to composers for dedicated compositions or purchases of music collections. The dedication of compositions can be understood as a personal author's promotion; by donating their work, the composers not only achieved their own presentation and dissemination of this music collection, but also expected some financial reward for the provided gift. The amount of remuneration then varied according to the financial possibilities of the recipient. If we compare the discovered information across Moravia and across the Central European area, we often come to interesting parallels that will be presented in this paper.
\end{abstract}

1 Die vorliegende Abhandlung geht teilweise aus der Forschung hervor, die im Rahmen des Doktorstudiums am Institut für Musikwissenschaften in Brünn durchgeführt wurde, siehe STUDENIČOVÁ, Hana. Městská hudebni kultura na Moravě v prédbělohorském obdobi. Moravská královská města ve středoevropských souvislostech. Dissertation. Brno: Masaryk-Universität, 2019. Präsentiert wurde dieser Aufsatz an der 54. Internationalen Musikologischen Konferenz in Brünn (54. International Musicological Colloquium Brno. Urban music culture in Central Europe ca. 1450-1670. 4.-6. 11. 2019, Brno). Neue Erkenntnisse, die während der weiteren Forschung in Archiven in Tschechien, Österreich und in der Slowakei entdeckt wurden in den Text Eingang. Diese neue Forschung wurde im Rahmen des Projekts VEGA 2/0034/17 The Image of Piety in Medieval Musical Culture in Slovakia (2017-2020) durchgeführt und weitere Forschungsaufenthalten und sprachliche Korrekturen wurden auch dank des Stipendiums von Hus-Stiftung ermöglicht. 


\section{Key words}

music dedications, Brno, Znojmo, Jihlava, Olomouc, books of municipal and church accounts, books with city correspondence, Orlando di Lasso, Jacob Handl Gallus, Franciscus Sale, Johann Knöfel, Christoph Demantius

In der mährischen Region blieben Musikalien aus den Chören von Pfarrkirchen im Zeitraum vor der Schlacht am Weißen Berg bis auf Ausnahmen nicht erhalten. ${ }^{2}$ Wichtige Informationen über das Repertoire auf Chören städtischer Pfarrkirchen könnten Musikinventare liefern, die jedoch nicht in allen Städten erhalten geblieben sind, bzw. nur für spätere Epochen existieren. ${ }^{3}$ Oft sind die einzigen Belege über konkrete Musikstücke in städtischen und kirchlichen Rechnungsbüchern, in Kopialbüchern oder in anderem Aktenmaterial vorhanden. Während der systematischen Durchforschung der oben genannten Quellen in Brünn, Znaim, Iglau und Olmütz, also in den vier größten mährischen Königsstädten, wurde eine große Anzahl an Eintragungen über Ankäufe von Musikalien oder Musikwidmungen an Stadträte entdeckt. ${ }^{4}$

Die Widmung von Kompositionen lässt sich als persönliche Autorenpropagation auffassen; Komponisten erzielten nicht nur ihre eigene Präsentation und Verbreitung des jeweiligen Werkes, sondern sie erwarteten für die gewährte Gabe zugleich eine finanzielle Belohnung. Ihre Höhe schwankte je nach den finanziellen Verhältnissen des Rezipienten, in diesem Falle nach den finanziellen Möglichkeiten der Städte. ${ }^{5}$ Beim Vergleich

2 Eine Ausnahme bilden zwei polyphone Handschriften (Chorbücher) aus der St.Jakob-Kirche in Brünn aus der Zeit um 1550 (zu finden in Brünner Stadtarchiv, Handschriftsammlung, Fond V 2 St. Jakober-Bücherei, Sign. 15/4 und 14/5); siehe HORYNA, Martin - MAŇAS, Vladimír. Two Manuscripts of Polyphonic Music in Brno from the Mid-Sixteenth Century. Early Music 40, 2012, Nr. 4, S. 553-575; MAŇAS, Vladimír. Rukopisy renesanční polyfonie - zapomenutá a přitom cenná součást svatojakubské farní knihovny. In Brno v minulosti a dnes: př́spěvky $k$ dějinám a výstavbě Brna. Brno: Statutární město Brno, Archiv města Brna, 2013, Nr. 26, S. $39-49$.

3 Für die aktuellen Forschungsergebnisse über Musikinventarien siehe Monographie KAPSA, Václav MAŇAS, Vladimír - SPÁČILOVÁ, Jana. Hudební inventář́e raného novověku v českých zemích (im Druck).

4 Da sich die Erforschung an die vier größten mährischen Königsstädte (also Brünn, Znaim, Iglau und Olmütz) orientiert, werden die meisten Informationen über Musikalien und Widmungen gerade aus diesen vier Städten vorgestellt. Es erfolgt der Vergleich mit bisher bekannten oder neugefundenen Informationen aus anderen Städten im mitteleuropäischen Raum. Die Informationen über Widmungen der Komponisten den Stadträten oder den Pfarrkirchen in Böhmen und Mähren wurden bis jetzt noch nie zusammenfassend ausgewertet. Es gibt nur vereinzelte Vermerke in der Literatur, z. B. für den böhmischen Raum gibt es eine Monographie über die musikalische Geschichte der Stadt Eger - siehe RIESS, Karl. Musigeschichte der Stadt Eger im 16. Jahrhundert. Brünn: Rudolf M. Rohrer, 1935 - in dem er Widmungen der Kompositionen an Stadrat erwähnt, siehe S. 117-123.

5 Im Falle von Widmungen ist eine zeitgenössische sprachliche Unterscheidung unter den Termini „dedizieren“, „praesentieren" und „verehren“ notwendig. Bzw. ist es von Bedeutung, die Situationen zu unterscheiden, wann der Autor sein Werk namentlich einer einzelnen Person widmet oder es einer beliebigen anderen Person dediziert; aus der relevanten Fachliteratur für den mitteleuropäischen Raum siehe vor allem ROSE, Stephen. The Mechanisms of the Music Trade in Central Germany, 1600-40. Journal of the Royal Musical Association, Vol. 130, N. 1 (2005), S. 1-37; ŠEBESTA, Josef. Mecenášství renesančních Habsburků? Miscellanea z výročni konference České společnosti pro hudebni vědu 2008, Praha 2010, S. 25-30, hier S. 27; mit der terminologischen Problematik von Widmungen der Musikstücke beschäftigt sich Vladimír Maňas neulich im Text: MAŇAS, Vladimír. 
der ermittelten Informationen quer durch Mähren und den mitteleuropäischen Raum gelangt man oft zu interessanten Parallelen.

\section{Die Quellenbasis - Realität vs. ideale Situation}

Wie schon gesagt, die grundlegenden Informationen über verschickte Musikstücke befinden sich in Rechnungsbüchern und anderem Aktenmaterial, das in den Stadtarchiven der jeweiligen Städte ${ }^{6}$ und im Mährischen Landesarchiv in Brünn vorhanden ist.

Es gibt unterschiedliche Einträge, aus denen wir über die gewidmeten Musikstücke erfahren können. An erster Stelle handelt es sich um einen Brief, der an den Stadtrat geschickt wurde. In diesem Brief stellen sich die Komponisten selber und anschließend die eingeschickten Kompositionen vor. Zum Schluss drücken sie noch ihre Hoffnung aus, ihre Musikstücke würden gut angenommen. Das heißt, sie hoffen, dass sie dafür bezahlt werden. Bis jetzt sind nur drei solche Briefe bekannt, wobei der allerwichtigste ist ein Brief von Francisco Sale aus dem Jahre 1593, der an den Iglauer Stadtrat geschickt wurde. ${ }^{7}$

Der Stadtrat musste auf solche Briefe irgendwie reagieren und antworten. Auch diesmal wurden nur zwei Einträge in den Kopialbüchern entdeckt. In beiden Fällen handelt es sich um eine Antwort den Söhnen von Orlando di Lasso für eingeschickte Sammlung Magnum opus musicum ihres Vaters. Die Antwort schickte Brünner und Olmützer Stadtrat übereinstimmend im August 1606 ab. ${ }^{8}$ Anschließend tauchen diese Ausgaben in städtischen Rechnungsbüchern auf, die die bedeutendste Informationsquelle über Widmung der Musikstücke darstellen. ${ }^{9}$

Die letzten Quellen, die Widmungen in den mährischen Städten belegen, sind zwei Olmützer Musikinventaren aus den Jahren 1594 und 1602. ${ }^{10}$ Diese stellen die ältesten

Nicolaus Zangius: hudebnik přelomu 16. a 17. století. Na stopě neznámému. Brno: Masarykova univerzita, 2020, Kapitel Kompozice jako předmět reciprocity: rozsah a charakter média. Allgemein zur Problematik von Belohnungen siehe: ČAPSKÁ, Veronika. Výzkum raně novověké směny darů a prameny osobní povahy - k možnostem antropologizace ekonomických dějin střední Evropy. In Dějiny - teorie - kritika, Jg. 14, Nr. 2, Praha: Fakulta humanitních studií UK, 2017, S. 191-225; Anhand der erforschten Quellenbasis sollte der Begriff „Verehrung“ verwendet werden, der aber im heutigen Sprachgebrauch andere Konnotationen gewonnen hat, doch um die Tatsache an sich und den heutigen Sprachgebrauch zu berücksichtigen, wird in diesem Aufsatz der Begriff „Widmung“ bzw. das Verb „widmen“ benutzt.

6 Alle Namen der Archive und Fonds bleiben in der Originalsprache; Znaim: SOkA Znojmo, fond Archiv města Znojma - Nejstarší knihy a rukopisy (weiter nur AMZ); Iglau: SOkA Jihlava, fond Archiv města Jihlava (weiter nur AMJ), Olmütz: SOkA Olomouc, fond Archiv města Olomouc - knihy 1343-1945 (weiter nur AMO); Brünn: Archiv města Brna, fond A 1/3 Archiv města Brna - Sbírka rukopisů a úředních knih (weiter nur AMB, A 1/3).

7 Moravský zemský archiv Brno (weiter nur MZA), fond G 1 - Bočkova sbírka, Kart. 45, Sign. 8505; ausführlichere Beschreibung der Widmungen von Sale siehe S. 21-23.

8 Vergleiche S. 23-24.

9 Erhaltene Rechnungsbücher in Brünn (1523-1620), Znaim (1541-1620) und Olmütz (mit einigen Vorbehalten 1530-1630); in Iglau sind keine Rechnungsbücher erhalten geblieben.

10 SOkA Olomouc, fond Farní úřad sv. Mořice (dále jen FÚ sv. Mořice), Fundationsbuch der Kirche St. Mauritz, 1546, ehemalige Signatur FN 4 (weiter nur Fundationsbuch), Fol. 658r-659r (Cathalogus librorum pro 
erhaltenen Musikinventaren in Mähren und sind für die Erkenntnisse über die Betriebspraxis auf dem Chor von St. Mauritz und über die Geschichte der städtischen Schule von Belang. Ihre Einzigartigkeit hängt jedoch mit den Widmungen zusammen. Beide Inventare beinhalten sowohl handschriftliche Choralbücher und polyphone Sammelwerke als auch eine größere Menge von Renaissancedrucken. Gerade bei manchen Sammlungen befindet sich die Abkürzung "praesent:“ oder „pres:“(praesentatum) und das jeweilige Jahr. Es handelt sich um Jahre, in denen diese Drucke dem Stadtrat gewidmet wurden. Am Ende des Inventars aus dem Jahre 1602 sind weitere Einträge aus den Jahren 1603-1606 zu finden. Auch in diesem Falle handelt es sich um gewidmete Musikstücke, unter anderen sich auch die oben genannte Magnum opus musicum von Orlando di Lasso befindet, die nach Olmütz im Jahre 1606 geschickt wurde. ${ }^{11}$

\section{Gliederung}

Aus dem Zeitraum von 1560 bis 1620 sind in Mähren insgesamt über vierzig bis dato gefundene Einträge über die Widmung von Musikstücken an Stadträte vorhanden. Diese können in drei Kategorien unterteilt werden: In der ersten Gruppe handelt es sich um gedruckte Musikalien bekannter Komponisten. Meistens ist es auch gelungen, die Musikalien zu identifizieren. In der zweiten Gruppe befinden sich Musikalien, die von unbekannten bzw. lokalen Komponisten stammten und Ihre Werke deshalb nicht identifiziert werden konnten. Bei der dritten Gruppe handelt es sich um anonyme oder unbekannte Musikalien.

\section{Die erste Gruppe - meistens identifizierte Musikalien bekannter Komponisten}

In Iglau ist ein Brief aus dem Jahre 1562 erhalten geblieben, in dem der Komponist Johann Wircker aus der sächsischen Stadt Oschatz, dem Iglauer Stadtrat seine Kompositionen widmet. ${ }^{12}$ In dem Brief wird über einen Lobgesang der heiligen St. Ambrosius

usu templi ad D: Mauritium...); das erste Inventar verfasste 1594 Kantor Johannes Garletus zusammen mit dem Rektor der St. Mauritz-Schule Magister Andreas Obeslavius; bei dem jüngeren Inventar handelt es sich um eine Liste aller Musikalien, die Garletus kurz vor seinem Tod 1602 der Kirche gewidmet hat. Mehr zur Person von Johannes Garlet siehe: STUDENIČOVÁ, Hana. Moravská královská města, Bratislava a Vídeň: shody a odlišnosti v městském hudebním prostředí v 16. a na počátku 17. století. Musicologica Slovaca 2019, Jg. 10, Nr. 2, S. 202-203; zu den Olmützer Inventaren siehe z. B. SEHNAL, Jiř́i. Die Musik in Mähren gegen Ende des 16. Jahrhunderts und Jacobus Gallus. In Gallus Carniolus in Evropska Renesansa 1. Ljubljana: Slovenska akademija znanosti in umetnosti, 1991, S. 33-43.

11 SOkA Olomouc, FÚ sv. Mořice, Fundationsbuch, Fol. 659r (Magnum opus Musicum Orlandi de Lasso...).

12 SOkA Jihlava, AMJ, Sign. II A 10 (Am Osterabenth Anno 1562); mehr über die Persönlichkeit Johann Wircker siehe z B. EITNER, Robert. Wircker, Johann. In Biographisch-bibliographisches Quellen-Lexikon. Band 9. Graz: Akademische Druck- und Verlagsanstalt, 1959, S. 279 oder WEINHOLD, Liesbeth. Wircker, Johann. In 
und Augustinus (Te Deum) und auch über die Mottete Domine dirige gressus meos gesprochen, alles wurde für fünf oder sechs Stimme auf einem Pergament im Stil von Gesangbuch komponiert. ${ }^{13}$ Im Zusammenhang mit dem erhaltenen Brief aus Iglau könnte vorausgesetzt werden, dass der unbenannte Magister aus dem kurfürstlichen Kantorat, der nach Znaim im September 1561 das Gesangbuch einschickte und dafür 10 fl. einkassierte, eigentlich Johann Wircker sein könnte. ${ }^{14}$ Johann Wircker widmete noch 1563 dem Iglauer Stadtrat weitere Moteten auf Pergament; im erhaltenen Brief hat er sich jedoch als Kopist des Königs Maximilian in Breslau unterschrieben. ${ }^{15}$

Als die nächste eindeutig identifizierte Widmung in Mähren kann der Eintrag in Znaimer Rechnungsbüchern betrachtet werden. Pietro Giovanelli (auch Joanelli) schickte im August 1569 seine Sammlung Novi thesauri musici nach Znaim und für seine sechsstimmige „schöne einbundene und mitt gollt gezierte Moteten“ bekam er $8 \mathrm{fl} .17 \mathrm{gr} .1 \mathrm{~d} .{ }^{16}$ Aufgrund eines Eintrags in Znaimer Materialien kann man voraussetzen, dass Giovanelli seine Mottetensammlung auch nach Brünn schickte, und zwar im Juni 1569, also zwei Monate früher, als nach Znaim. ${ }^{17}$ Dieselbe Motettensammlung befindet sich auch im Musikinventar aus Olmütz aus dem Jahre $1594^{18}$ und aufgrund den Rechnungsbüchern kann bestätigt werden, dass die Stadt die Belohnung 10 Gulden im März 1570 ausbezahlte, Musikalien wurden dann der St. Mauritz-Kirche überlassen. ${ }^{19}$ Die Drucke von Giovanelli wurden z. B. auch

SADIE, Stanley - TYRRELL, John (eds.). The New Grove Dictionary of Music and Musicians. 2nd ed. New York: Grove, 2001, S. 445.

13 Dasselbe Manuskript mit der Mottete Dominie dirige gressus meos und Te Deum schickte Wircker am 18. März 1562 nach Thorn (Polen), siehe LESZCZYŃSKA, Agnieszka. W poszukiwaniu hanzeatyckiego sponsora: listy muzyków z przelomu XVI i XVII wieku do rad miejskich Torunia i Gdańsk. In JEŻ, Tomasz (ed.). Complexus effectuum musicologiae; studia Miroslao Perz septuagenario dedicate. Wydanie I. Kraków: Rapid, 2003, S. 239-247, vor allem S. 240; oder auch LESZCZYŃSKA, Agnieszka. Music and Musicians in Late-Renaissance Toruń. In KRASSOWSKI, Janusz (ed.). Musica Baltica: the music culture of Baltic cities in modern times. Gdańsk: Akademia Muzyczna im. Stanisława Moniuszki, Gdańsk, 2010. Prace specjalne, S. 165-175, vor allem S. 173; Man kann vermuten, dass es sich um Handschriften im Stil von Chorbuch handelt; Wircker widmete etwas Ähnliches z. B. im Jahre 1557 dem Stadtrat in Freiberg (Freiberg/Sachsen, Geschwister-Scholl-Gymnazium, Andreas-MöllerBibliothek, Ms. 11) oder im Jahre 1560 dem Stadtrat in Augsburg (Bayerische Staats Bibliothek, Musikabtheilung, Sign. Mus. ms. 59), zugänglich online <http://daten.digitale-sammlungen.de/0007/bsb00078963/images/

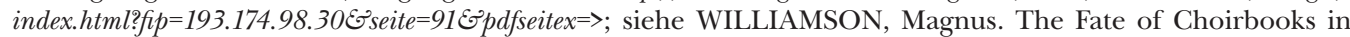
Protestant Europe. Journal of the Alamire Foundation, 2015, Vol. 7, N. 2, S. 117-131, hier vor allem S. 118-119.

14 SOkA Znojmo, AMZ, Zahlungsbuch, Sign. AMZ-II 251-2, Fol. 75r (13. Sep. 1561: ein Magistro aus kurfürsten zu Sachsen Cantorey weg eines Cantionals $10 \mathrm{fl}$.).

15 SOkA Jihlava, AMJ, Sign. II A 10 (12. Octob. 1563); es kann sich höchstwahrscheinlich um dieselbe Handschrift handeln, wie die, die im Jahre 1563 dem Albrecht von Preußen gewidmet wurde; siehe WILLIAMSON, op. cit., S. 118.

16 SOkA Znojmo, AMZ, Zahlungsbuch, Sign. AMZ-II 252, Fol. 32r (13. Aug. 1569: Einem Musico von Wenedig, mitt Namen Petrus Joanelli von Gardi, so sechs vocum shene einbundene und mitt gollt gezierte Motetenn einem E: Rath zugeschickt verehrt $8 \mathrm{fl} .17 \mathrm{gr} .1 \mathrm{~d}$.).

17 AMB, A 1/3, Ratsrechnungen, Ms. 409, Fol. 6v (1569: 21. Juni ist umb 6 Gesang biecher geben worden thuett $15 \mathrm{fl.}$.).

18 SOkA Olomouc, FÚ sv. Mořice, Fundationsbuch, Fol. 658r (Thesaurus Musicus Petri Joanelli).

19 SOkA Olomouc, AMO, I C 1 a Stadtrechnungsbuch (1560-1574), Sign. 68, Fol. 242r (F VI ante Quasimodo 1570: wegen der Partes, so man in die Kirchen zu S. Mauriz geben verehrt $10 \mathrm{fl}$.). 
von einem gewissen Geschäftsmann (Jacob Scholz) aus Breslau nach Toruń ${ }^{20}$ oder nach Danzig $^{21}$ geschickt. Giovanelli war auch für einige Zeit in Wien tätig, wo er im Jahre 1565 das kaiserliche Privilegium als Musiker und Drucker bekam. ${ }^{22}$

Mit Mähren ist die Persönlichkeit von Jacob Handel Gallus verbunden. Es ist bekannt, dass er sich um 1579 im Prämonstratenser Kloster in Klosterbruck (bei Znaim) und in Obrowitz (bei Brünn) aufhielt. In Klosterbruck amtierte Sebastian Freytag von Čepiroh als Abt, eine der führenden Persönlichkeiten in der Geschichte dieses Klosters; in Obrowitz gab es den Abt Schönauer, mit dem er gute Beziehungen pflegte. ${ }^{23}$ Seine Kontakte mit der Stadt Brünn belegt die Tatsache, dass seine siebenstimmige Motette Undique flammatis, mit der er die Wahl des neuen Olmützer Bischofs Stanislav Pavlovský feierte, ${ }^{24}$ im Jahre 1580 dem Brünner Stadtrat gewidmet wurde. ${ }^{25}$ Gleich im Januar 1581 schickte Handl seine erste gedruckte Messesammlung Selectiores quaedam missae dem Abt im Klosterbruck (also an Sebastian Freytag), wofür er 10 Taler bekam. ${ }^{26}$ Dieselbe Sammlung widmete er im Jahre 1583 der Stadt Olmütz, ${ }^{27}$ sowie sein tomus primus, secundus und tertius aus der Sammlung Operis Musici im Jahre 1588. ${ }^{28}$ Einen vierten Band legte er am Ende des Jahres 1590 in Olmütz vor und bekam dafür im Januar 15915 fl. als Belohnung. ${ }^{29}$

20 Archiwum Państwowe in Toruń, Kat II, X/2. S. 61 (24. April 1571); nach LESZCZYŃSKA, Agnieszka. Music and Musicians in Late-Renaissance Toruń, op. cit., S. 173.

21 Archiwum Państwowe in Gdańsk, Akta Miasta Gdańska, 300/36, Sign. 57 (26. Juli 1571); nach LESZCZYŃSKA, Agnieszka. Music and Musicians in Late-Renaissance Toruń, op. cit., S. 173; Ich bedanke mich beim Herrn Vladimir Maňas, dass er mich darauf aufmerksam gemacht hat.

22 KOPPITZ, Hans Joachim (ed.). Die kaiserlichen Druckprivilegien im Haus-, Hof- und Staatsarchiv Wien: Verzeichnis der Akten vom Anfang des 16. Jahrhunderts bis zum Ende des Deutschen Reichs (1806). Wiesbaden: Otto Harrassowitz Verlag, 2008, S. 264.

23 Über Handel und seine Wirkung in Mähren siehe STRAKOVÁ, Theodora. Vokálně polyfonní skladby na Moravě v 16. a na počátku 17. století. 1: Příspěvek k poznání hudebního života na Moravě v době předbělohorské. Časopis Moravského muzea: vědy společenské, 1981, Nr. 66, S. 165-178; 2: Jakob Hand-Gallus v českých zemích. Časopis Moravského muzea: vědy společenské, 1982, Nr. 67, S. 85-95; oder SEHNAL 1991, op. cit.; ein aktueller Titel über die Kontakte von Handel in Mähren z. B. MAŇAS, Vladimír. Rudolfínská Morava (im Druck) oder über sein Werk MOTNIK, Marko. Jacob Handl-Gallus: Werk - Überlieferung - Rezeption; Mit thematischem Katalog. Tutzing: Verlegt bei Hans Schneider, 2012 und zum Problematik der Distribution von Musikdrucken hier vor allem S. 50-60.

24 Ausführlich: siehe Edition und Vorwort GALLUS-HANDL, Jacob. Undique flammatis, Epicedion harmonicum. In DESMET, Marc - MOTNIK, Marko - GRABNAR, Klemen (eds.). Monumenta artis musicae Sloveniae. Ljubljana: Slovenska Akademija Znanosti in Umetnosti, 2015.

25 AMB, A 1/3, Ratsrechnungen, Ms. 431, Fol. 17r (17. Dec. 1580: dem Jacob Componist das er meinen Herr 7 vocum verehrt hat verehrt hat geben $5 \mathrm{fl}$.). Diese Widmung wurde in Rechnungsbüchern und mit der Mottete Undique flammatis von Hana Studeničová und Vladimír Maňas identifiziert.

26 MZA, fond E 57 - Premonstráti Louka, Kart. 3, Ms. 4, Fol. 1r; Transkription des Briefes siehe SCHRAM, Wilhelm. Der Abt von Kloster-Bruck Freitag v. Cziepiroh (1573-1585). Zeitschrift des Vereines für die Geschichte Mährens und Schlesiens, 3, 1899, S. 312-324.

27 SOkA Olomouc, FÚ sv. Mořice, Fundationsbuch, Fol. 658r (Opus missarum Jacobi Handelii Praesent: Anno 83); in Rechnungsbüchern wurde dieser Eintrag nicht gefunden.

28 SOkA Olomouc, AMO, I C 1 a Stadtrechnungsbuch (1575-1589), Sign. 69, Fol. 268r (F VI post Trium Regum 1588: Jacobo Handl vorehret 5 fl.); SOkA Olomouc, FÚ sv. Mořice, Fundationsbuch, Fol. 658r (Tomus 1, 2 et 3 operis Jacobi Handelii Cantori praesentatus Anno 1588).

29 SOkA Olomouc, AMO, I C 1 a Stadtrechnungsbuch (1590-1610), Sign. 70, Fol. 11v (F VI ante Epiphaniam 
Höchstwahrscheinlich schickte Handl im Oktober 1587 und im Dezember 1590 dieselbe Sammlungen auch nach Brünn. ${ }^{30}$ Ein unbenanntes Werk widmete er im Jahre 1582 auch z. B. in Neu Titschein, wobei er von der Stadt 6 fl. erhielt. ${ }^{31}$

Der nächste Autor, der seine Stücke an mährische Städte schickte, ist Johann Knöfel. In Znaim präsentierte er im September 1574 sein erstes gedrucktes Werk Dulcissimae quaedam Cantiones. ${ }^{32}$ Als Organist der Prager Neustadt widmete er 1592 seine Sammlung Novae melodiae der Kirche in Mährisch Trübau. ${ }^{33}$ In demselben Jahr wurde auch eine Ausgabe von 5 fl. an Johann Knöfel ,für etlich muteten “ in Eger belegt. ${ }^{34}$ In städtischen Rechnungsbüchern aus Olmütz befindet sich ein Eintrag über eine Belohnung einem unbekannten Komponisten für eingeschickte Musikstücke. Dieser ist mit Oktober 1592 datiert und es handelt sich höchstwahrscheinlich um Johann Knöfel und seine Sammlung Novae melodiae. ${ }^{35}$ Dieselbe Sammlung schickte er ein Jahr später nach Znaim und hier wurde er auch als „Organist bey S. Heinrich in der Neuen Stadt zu Prag“ eingetragen. ${ }^{36}$ Aufgrund dieser Informationen ist es sehr wahrscheinlich, dass Knöfel seine Sammlung auch nach Brünn schickte. Am 14. Mai 1593, also einen Tag früher als in Znaim, findet man in Brünner Rechnungsbücher einen Eintrag über Belohnung eines Kantors - höchstwahrscheinlich Knöfel - für eine eingeschickte Partes. ${ }^{37}$

In der mährischen Region befinden sich auch zahlreiche Einträge über das Werk von Francisco Sale. ${ }^{38}$ Am 8. Mai 1593 zahlte der Znaimer Stadtrat 2 fl. als Belohnung für

domini 1591: Jacobo handl vor seine bücher verehret 5 fl.); SOkA Olomouc, FÚ sv. Mořice, Fundationsbuch, Fol. 658v (Quartus tomus Musici operis 4, 5, 6, 8, plurimum vocum Jacobi Handelii. Incipiens pars á Sanctis, praesentatus cantori Anno Salutis nostrae 1590).

30 AMB, A 1/3, Ratsrechnungen, Ms. 445, Fol. 13 r (October1587: Einem Botten so die Partes von Prag meinen Herrn zur verehrung gebracht Ihm geben 1 fl.); AMB, A 1/3, Ratsrechnungen, Ms. 451, Fol. 19r (den 12. December 1590: dem Jacob Händl so meyn herrn die Partes von Prag vor send und zugeschickt Ihme wirdderumb vor erdt 12 fl.).

31 Nach BECK, Josef. Geschichte der Stadt Neutitschein und deren Umgebung. Neutitschein: Schnellpressendruck von J. R. Enders, 1854, S. 233; siehe auch MAŇAS, Vladimír. Inventář hudebnin farního kostela v Novém Jičíně z roku 1630. Musicologica Brunensia, 2012, Jg. 47, Nr. 2, S. 73-77, vor allem S. 73; was das Einschicken von den Kompositionen von Gallus angeht, gibt es hier Ähnlichkeiten, die in vielen mitteleuropäischen Städten und Klostern zu beobachten sind (z. B. Görlitz, Naumburg, Leipzig oder Kremsmünster), aber auch im tschechischen Gebiet (Rakonitz); siehe MOTNIK, Marko. Jacob Handl-Gallus, op. cit., S. 50-58.

32 SOkA Znojmo, AMZ, Zahlungsbuch, Sign. AMZ-II 252, Fol. 235r (18. Sep. 1574: Einem Magistro von Legniz umb dedizierte Moteten 1 fl.).

33 HORKÝ, Josef Edmund. Versuch eines historischen Jahrbuches der Stadt und Herrschaft Mährisch Trübau bis zu 1700ten Jahr., I. Abtheilung. Geschrieben Anno 1812, Fol. 125a (AMB, Sbírka rukopisů knihovny Mitrovských, Sign. A 26, Fol. 125r); nach SEHNAL, Jiří. Hudební inventář kostela v Moravské Třebové z konce třicetileté války. Hudebni věda, 2015, Jg. 52, Nr. 1, S. 5-28, vor allem S. 15.

34 Nach RIESS, op. cit., S. 122.

35 SOkA Olomouc, AMO, I C 1 a Stadtrechnungsbuch (1590-1610), Sign. 70, Fol. 53v (F VI post Lucae Evangelistae 1592: Einem Studioso wegen etlicher Partes verehrett 1 fl. $15 \mathrm{gr} .3$ d.); SOkA Olomouc, FÚ sv. Mořice, Fundationsbuch, Fol. 658v (Novae Melodiae 8, 7, 6 et 5 vocum authore Johanne Knefelio praesentatus Anno 1594); wahrscheinlich geht es um einen Datierungfehler im Musikinventar, weil es 1594 keinen Eintrag über eingeschickte Musikstücke in den Olmützer Rechnungsbüchern gibt.

36 SOkA Znojmo, AMZ, Zahlungsbuch, Sign. 253, Fol. 653r (15. May 1593: Dem Johann Kneiffl Organist bey S: Heinrich in der Neuen Stadt zu Prag umb etliche Moteten die er einem ersamen Rath von Prag hieher gesendet 18 gr.).

37 AMB, A 1/3, Ratsrechnungen, Ms. 457, Fol. 9v (1593: 14. May einem kantores so etlich bartis verehrt 2 fl.).

38 Alle herausgegebenen Sammlungen von Sale (insgesamt acht von denen wurden bei Georg Nigrin in Prag 
eingeschickten fünf- und sechsstimmige Motteten an Francisco Sale aus. ${ }^{39}$ Es handelt sich um den Druck Sacrarum cantionum, der im Jahre 1593 in Prag vom Georg Nigrin herausgegeben wurde. Aufgrund eines Eintrags in Znaimer Materialien kann vorausgesetzt werden, dass die Entlohnung des Komponisten aus Prag in Brünner Rechnungsbüchern aus dem gleichen Jahr auch für Francisco Sale könnte bestimmt werden. ${ }^{40}$ Der Druck Sacrarum cantionum schickte Sale auch nach Iglau, worüber ein erhaltener Brief vom 18. Juli desselben Jahres Zeugnis gibt. ${ }^{41}$ Zum letzten Mal konnte die Ausgabe für dieselbe Sammlung in Eger festgestellt werden. Von dortigem Stadtrat soll Sale 5 fl. bekommen haben, die jedoch erst nach einer Mahnung bezahlt wurden. ${ }^{42}$

Eine Erwähnung über die Musikstücke von Sale liefern auch Quellen in Olmütz. Die einzelnen Sammlungen zu identifizieren erschwert jedoch sowohl die Anzahl von Einträgen als auch eine relativ enge Zeitepoche. Im Mai 1593 findet sich in den Rechnungsbüchern einen Eintrag für eingeschickte Musikstücke. Laut dem Inventar handelt es sich wahrscheinlich um denselben Druck Sacrarum cantionum, der auch nach Znaim, Iglau und Eger von Sale geschickt wurde. ${ }^{43}$ Am Anfang des Jahres 1594 schickte Sale dem Olmützer Stadtrat den zweiten Band Officiorum Missalium..$^{44}$ Zwei Jahre später folgte dann einen weiteren Druck, konkret handelt es sich um die Sammlung Tripertiti operis Officiorum Missalium, die 1596 von Georg Nigrin in Prag herausgegeben wurde. ${ }^{45}$ Im gleichem Jahr erhielte eine Sammlung von Sale auch das Brünner Stadrat. ${ }^{46}$ Der letzte Eintrag über die Kompositionen von Sale erscheint im Olmützer Inventar mit dem Hinweis auf das Jahr 1598, in dem Sale dem Stadtrat die Sammlung Patrocinium musices schickte und höchst-

gedruckt) handelte Petr Daněk ab, siehe DANĚK, Petr. Historické tisky vokální polyfonie, rané monodie, hudebni teorie a instrumentálni hudby v českých zemích do roku 1630: se soupisem tisků z let 1488-1628 uložených v Čechách. Praha: KLP, 2015, S. 43-54.

39 SOkA Znojmo, AMZ, Zahlungsbuch, Sign. AMZ-II 253, Fol. 652v (8. May 1593: dem Francisco Sale kaiserlicher Musico umb etliche fünff und sechstimmige Moteten die er von Prag alher gesendet und einem ersamen Rath verehret gegeben $2 \mathrm{fl}$.).

40 AMB, A 1/3, Ratsrechnungen, Ms. 455, Fol. 17r (den 15. Februarii 1593 einem so meinen herrn partus hat verehrt von Prag verehrt 2 fl.); Ebenda (den 22. Februarii von bartisen ein zu binden geben $1 \mathrm{fl}$.).

41 MZA, fond G 1 - Bočkova sbírka, Kart. 45, Sign. 8505 (18. Juli 1593).

42 RIESS, op. cit., S. 122-123 (21. August 1593: wegen etlicher partes 5 fl. Verehrt); nach DANĚK, op. cit., S. 46.

43 SOkA Olomouc, AMO, I C 1 a Stadtrechnungsbuch (1590-1610), Sign. 70, Fol. 58v (F VI ante Exaudii 1593: verehrung gegen etlichen zuegeschickten partibus $1 \mathrm{fl}$.); SOkA Olomouc, FÚ sv. Mořice, Fundationsbuch, Fol. 658v (Sacrarum Cantionum omnis generis Instrumentis accomodant Franc: Sale liber 1 praes: 94); (wahrscheinlich geht es um einen Datierungfehler im Musikinventar).

44 SOkA Olomouc, AMO, I C 1 a Stadtrechnungsbuch (1590-1610), Sign. 70, Fol. 76v (F VI post trium Regum Anno 1594: Francisco Sale wegen verehrten partes 2 fl.); SOkA Olomouc, FÚ sv. Mořice, Fundationsbuch, Fol. 658v (Officiorum Missalium liber 2 Francissi Sale...).

45 SOkA Olomouc, AMO, I C 1 a Stadtrechnungsbuch (1590-1610), Sign. 70, Fol. 119v (F VI post Conver: Pauli 1596: Francisco Sale wegen verehrten Partes 2 fl.); SOkA Olomouc, FÚ sv. Mořice, Fundationsbuch, Fol. 658v (Missalia 5 et 6 vocum de sanctis, Franc: Sale tripartiti operis liber 1.).

46 AMB, A 1/3, Ratsrechnungen, Ms. 461, Fol. 13r (den 24. Januari 1596 einem von Prag umb 5 partes verehrt $4 \mathrm{fl}$.); es lässt sich nicht beweisen, um welche Sammlung es sich handelte, doch angesichts der Datierung wird eher nicht vermuten, dass seine weitere Sammlungen aus dem Jahre 1596 gleich im Januar gedruckt wurden, deshalb liegt er an der Hand, dass es um die Sammlung Officiorum Missalium liber secundus aus dem Jahre 1594 ging. 
wahrscheinlich im selben Jahr auch das nächste Band Officiorum Missalium. ${ }^{47}$ Eine dieser Kompositionen sandte Sale wahrscheinlich auch im Jahre 1598 nach Brünn. ${ }^{48}$

Der nächste Autor, der seine Kompositionen nach Mähren schickte, ist Christoph Demantius. Konkret handelt es sich um die Sammlung Trias precum vespertinarum, die 1602 herausgegeben wurde. Der erste Eintrag findet man in Wien, wo er am 28. Juli 1603 „etliche Partes dediziert." ${ }^{9}$ Nur ein paar Tage später findet man Nachricht über gewidmete Musiksammlung von Demantius in Znaim. ${ }^{50}$ In Brünner Rechnungsbücher gibt es eine Ausgabe von 3 fl. für eine sechsstimmige Vesper am 15. November $1603 .{ }^{51}$ Obwohl der Komponist nicht konkret erwähnt wurde, handelt es sich auf jeden Fall um dieselbe Sammlung. Auch im November gibt es einen Eintrag für die Musikstücke von Demantius in Olmütz. ${ }^{52}$ Diese Information bestätigt auch das Olmützer Musikinventar, die Sammlung Trias precum vespertinarum ist hier als Magnificamina eingetragen. ${ }^{53}$

Eine seltene Erwähnung in Mähren findet man über die Widmung der Musikstücke von Nicolaus Zangius. Er schickte seine Kompositionen im August 1604 nach Brünn und im Jahre 1616 auch nach Olmütz. ${ }^{54}$ In anderen mährischen Städten gibt es keine Einträge über eine andere Widmung des Musikwerkes von Zangius.

Interessante Zusammenhänge sind am Beispiel der Kompositionen von Orlando di Lasso zu sehen. Seine Musikdrucke verbreiteten sich in Mähren noch zeit seines Lebens. Im Olmützer Musikinventar ist z. B. der Eintrag über die Sammlung Selectissimae cantiones von $1589 \mathrm{zu}$ finden. ${ }^{55}$ Nichtweniger interessant ist die Verbreitung seines Werkes

47 SOkA Olomouc, AMO, I C 1 a Stadtrechnungsbuch (1590-1610), Sign. 70, Fol. 158v (Feria VI post Ascensis Domini 1598: Francisco Sale verehrt werden 5 fl.); SOkA Olomouc, FÚ sv. Mořice, Fundationsbuch, Fol. 658v (A: 98 die 21. Aug. in folio Regali Missa de Nativ: authore Francisco Sale); Ebenda, Fol. 658v (Officiorum Missalium partes 5 eodem Authore); es ist nicht gelungen, die Ausgabe aus dem 21. August in städtischen Rechnungsbüchern ausfindig zu machen; möglicherweise geht es um einen Fehler und Francisco Sale schickte die Sammlung Officiorum Missalium liber III und Patrocinium musices zusammen.

48 AMB, A 1/3, Ratsrechnungen, Ms. 467, Fol. 11r (2. May 1598: mehr einem von Prag das meinen H. etliche Partes verehret hat, Trinkgelt verehret $6 \mathrm{fl}$.).

49 Wiener Stadt- und Landesarchiv, Oberkammeramtsrechnungen (weiter als OKAR), Sign. B 1/1: 129, Anno 1603, Fol. 100v (dem 28. Julii gab ich dem Christophen Demanto, Musici umb daß er ainem Edlen hochweisen Statt Rath etliche partes dediciert... $7 \mathrm{fl}$.)

50 SOkA Znojmo, AMZ, Zahlungsbuch, Sign. AMZ-II 254, Fol. 378v (2. Aug. 1603: Einem Musico nahmend Christophorius Daemantius von Zittau wegen zugeschikten Partes verehret $2 \mathrm{fl}$.).

51 AMB, A 1/3, Ratsrechnungen, Ms. 477, Fol. 17v (15. Nov. 1603: Einem Componisten so in 6 partes eine Vesper in die Khirchen zu S. Jacob verehrt geben $3 \mathrm{fl}$.).

52 SOkA Olomouc, AMO, I C 1 a Stadtrechnungsbuch (1590-1610), Sign. 70, Fol. 290v (28. Nov. 1603: Christophoro Demantio Musico umb prasentirte partes verehret $1 \mathrm{fl}$.).

53 SOkA Olomouc, FÚ sv. Mořice, Fundationsbuch, Fol. 659r (Magnificamina 6 vocum Authore Christoph Demantio). 54 AMB, A 1/3, Ratsrechnungen, Ms. 479, Fol 13v (21. Aug.1604: dem Componisten Sangij vererth 6 gantze Talle N P 70 gr. ... 6 fl. 12 gr. 6 d.); laut Vladimír Maňas handelt es sich um einen Kölner Druck mit dem Titel Kurtzweilige Neue Teutsche Weltliche Lieder mit vier Stimmen componirt aus dem Jahre 1603; SOkA Olomouc, AMO, I C 1 a Stadtrechnungbuch (1611-1630), Sign. 71, Fol. 125r (den 14. Octobris 1616: H. Zangio wegen E. E. Rath dedicirten Officii veröhrt $5 \mathrm{fl}$.); höchstwahrscheinlich handelt es sich um ein Manuskript mit Messen. Für die Konsultation bedanke ich mich beim Herrn Vladimír Maňas; mehr über Leben und Werk von Zangius, ebenso über seine Dedikationen an bedeutende Mäzene siehe MAŇAS 2020.

55 SOkA Olomouc, FÚ sv. Mořice, Fundationsbuch, Fol. 658r (Selectissime Cantiones 4, 5 , 6 et plurium vocum Orlandum di Lassum praesentatae A: 89); in Rechnungsbüchern wurde dieser Eintrag bis heute nicht gefunden. 
nach seinem Tod, vor allem mithilfe seiner zwei Söhne. Ferdinand und Rudolf di Lasso schickten die Sammlung Magnum opus musicum an Stadträte quer durch Mitteleuropa.

In Mähren befindet sich der erste Eintrag über eine Widmung von Brüdern di Lasso in Brünn. Die Stadt bezahlte im Jahr 1606 für die Sammlung Magnum opus musicum 30 fl. aus. ${ }^{56}$ In Brünn ist auch ein Brief erhalten geblieben, in dem sich die Stadtrat für einen eingeschickten Druck bedankt. ${ }^{57}$ Dieselbe Sammlung wurde im August 1606 auch nach Olmütz geschickt. ${ }^{58}$ Es ist auch ein Dankbrief vorhanden ${ }^{59}$ und das Stück Magnum opus musicum ist auch im Musikinventar beim St. Mauritz zu finden. ${ }^{60}$ Diese Sammlung ist z. B. in Kremsier ${ }^{61}$ oder bei den Brünner Augustinern überliefert. ${ }^{62}$

Nicht nur in Mähren, sondern im ganzen mitteleuropäischen Raum sind die Nachrichten über den Empfang der Sammlung von Lasso zu finden. Die erste Erwähnung stammt aus Graz aus dem Jahre 1604;63 ein Jahr später wurde die Sammlung Magnum opus musicum nach Nürnberg geschickt. ${ }^{64}$ Auch in Wien in den Kammerbüchern vom Oktober 1605 gibt es einen Eintrag über einen Bürger, der die gleiche Sammlung von München nach Wien brachte. ${ }^{65}$ Ähnlich findet man die Ausgaben für die Sammlung in Schweinfurt, Bayreuth, Augsburg ${ }^{66}$ und auch z. B. in Klagenfurt ${ }^{67}$ oder in Freiberg. ${ }^{68}$

56 AMB, A 1/3, Ratsrechnungen, Ms. 483, Fol. 14v (19. Aug. 1606: Ferdinando und Rodolpho de Laßo verehrt wegen der Mutteten $30 \mathrm{fl}$.); siehe auch SEHNAL, Jiří. Hudba v magistrátních účtech Brna do konce třicetileté války. In Historická Olomouc a jeji současné problémy IV. Olomouc: Palacký-Universität, 1983, S. 341.

57 AMB, A 1/3, Kopiarbuch, Ms. 88, Fol. 550v-551r.

58 SOkA Olomouc, AMO, I C 1 a Stadtrechnungsbuch (1590-1610), Sign. 70, Fol. 358r (25. Aug. 1606: Ferdinando et Rudolpho Gebrüdern de Lasso weg Zuegeschickten Magni Operis ihrers Vattern Orlanti Verert 15 fl.).

59 SOkA Olomouc, AMO, I B 8 Kopiarbuch (1600-1606), Sign. 199, Fol. 368r.

60 SOkA Olomouc, FÚ sv. Mořice, Fundationsbuch, Fol. 659r (Magnum Opus Musicum Orlandi de Lasso...).

61 Arcibiskupství olomoucké, Arcidiecézní muzeum Kroměříž, Sign. A 110-A 115; Ferdinand und Rudolf de Lasso haben im Jahre 1606 die Kompositionen von ihrem Vater Orlando auch an Kardinal Dietrichstein eingeschickt (Brief vom 23. 8. 1606, in dem der Kardinal dem Erasmus Heydeli anordnet, die Belohnung 30 fl. auszuzahlen, siehe MZA, fond G 2 - Nová sbírka, Sign. 228/50; nach SEHNAL, Jiří. Hudba na dvoře olomouckých biskupů od 13. do poloviny 17. století. Časopis vlasteneckého spolku musejního v Olomouci, Nr. 60, 1970, S. 76); es kann aber nicht nachgewiesen werden, ob der erhaltene Druck Magnum opus musicum aus Kremsier (Sign. A 110-A 115) tatsächlich das erhaltene gewidmete Exemplar ist.

62 Heutzutage befindet sich der Druck Magnum opus musicum aus der Augustinern Klosterbibliothek in der Musikabteilung des Mährischen Landesmuseums in Brünn, Sign. A 20 527a-e; siehe STUDENIČOVÁ, Hana. Q. In Search of musicalia from the Baroque Library of the Augustinian Eremites in Brno. Musicologica Brunensia, 2018, Jg. 53, Nr. 2, S. 16.

63 FEDERHOFER, Hellmut. Musikpflege und Musiker am Grazer Habsburgerhof der Erzherzöge Karl und Ferdinand von Innerösterreich: 1564-1619. Mainz: B. Schott's Söhne, 1967, S. 244.

64 LEWIS HAMMOND, Susan. Editing music in early modern Germany. London: Routledge, 2016, S. 167.

65 Wiener Stadt- und Landesarchiv, OKAR, Sign. B 1/1: 131, Anno 1605, Fol. 106rv.

66 LEWIS HAMMOND, op. cit., S. 167-168.

67 FEDERHOFER, Hellmut. Italienische Musik am Hofe des Fürstbischofs von Gurk, Johann Jakub von Lamberg (1603-1630). In OLSCHKI, Leo S. Collectanea Historiae Musicae. II. Florentiae: Leonis S. Olschki, 1956, S. 166.

68 BOETTICHER, Wolfgang. Orlando di Lasso und seine Zeit 1532-1594: Repertoire - Untersuchungen zur Musik der Spätrenaissance: mit 317 Notenbeispielen. Bd. 1, Monografie. Kassel: Bärenreiter-Verlag, 1958, S. 809. 


\section{Die zweite Gruppe - nicht identifizierte Musikalien von unbekannten oder lokalen Komponisten}

Die zweite Gruppe bilden Autoren, deren Namen zwar bekannt sind, dennoch wurden ihnen keine Musikstücke bis jetzt zugeordnet. Nur wenige Daten sind über den Musikkomponisten Christoph Keckricz bekannt, der 1584 von Olmütz eine Belohnung in Höhe von $1 / 2$ fl. bekam. ${ }^{69}$

Aus den Kantoren, die in den städtischen Schulen tätig waren, war z. B. der Schulmeister von St. Nikolaus, Georgius Wolffsperger, auch als Komponist tätig. Er widmete 1588 seine Motteten der Stadt Znaim und auch ein Jahr später officium Missae ${ }^{70}$ Eine Belohnung in gleicher Höhe wurde auch dem Benedikt Lelkowius ausbezahlt, der als Kantor bei St. Michael in Znaim tätig war und widmete 1592 dem Stadtrat seine „Motteten von der Geburt Jesu Christi. “71

Eine der letzten teilweise bereits identifizierten Widmungen befindet sich in Olmützer Rechnungsbücher. Es handelt sich um die Widmungen von Abraham Nymphaeus (Nimphaeus); im Jahre 1615 widmete er seine Messeoffizia für 24 Stimmen, ein Jahr später sein Te Deum laudamus und im Jahre 1620 Motteten dem Olmützer Stadtrat. ${ }^{72}$

69 SOkA Olomouc, AMO, I C 1 a Stadtrechnungsbuch (1575-1589), Sign. 69, Fol. 184v (F VI post Felicis 1584: Christophoro Keckriczio Componisten verehrtt 1/2 fl.); einzige Gemeinsamkeiten bietet näher unbekannter Komponist Christoph Keckeritz (auch Köckeritz, Gökeritz), Abschrift seiner Musikstücke befindet sich in der Quelle aus Aussig Numero Arythmetico notata Series aus dem Jahre 1588; mehr über diese Quelle siehe DANĚK, Petr - BAŤA, Jan. Numero Arithmetico notata Series officiorum pro Choro Ustensi (1588). Musicologica Istropolitana, Jg. 2011-2012, Nr. X-XI, S. 45-67, vor allem S. 54; Christoph Kökritius sandte seine Kompositionen in Jahren 1582 und 1584 auch an den Stadtrat in Kremnitz, siehe ZAVARSKÝ, Ernest. Príspevok k dejinám hudby v Kremnici I. Hudobný archív, Jg. 1977, Nr. 2, S. 87-88; Zavarský erwähnt, dass Kökritius als Musiker in St. Mauritz Kirche in Olomouc unterschrieben ist; Quellen aus Olmütz bestätigen diese Information bisher nicht. Manche Musikstücke von Keckericz befinden sich in der Handschriftensammlungen in der Stadtbibliothek zu Breslau, heutzutage Sammlung Bohn (Staatsbibliothek zu Berlin), siehe CHARTERIS, Richard. Newly discovered music manuscripts from the private collection of Emil Bohn. American Institute of Musicology, Holzgerlingen: Hänssler Verlag, 1999, S. 291.

70 Georgius Wolffsperger wirkte als Schulmeister bei St. Nikolaus in Znaim 1585-1589; 1588 widmete er seine Motteten der Stadt und bekam dafür 1 fl., siehe SOkA Znojmo, AMZ, Zahlungsbuch, Sign. AMZ-II 253, Fol. 377r (16. July 1588: Mutetn: Dem Schulmeister bey S. Nicolao umb dedicierte Mutteten 1 fl.); als der ehemalige Schulmeister schickt Wolffsperger nach Znaim im Jahre 1589 seine Officium Misse, siehe SOkA Znojmo, AMZ, Zahlungsbuch, Sign. AMZ-II 253, Fol. 434v (23. Juni 1589: dem Georg Wolffsperger gewesenen Schulmaister alhie bei S. Nicolau gegeben umb verehrtes officium Misse $1 \mathrm{fl}$.).

71 Benedict Lelkowius wirkte als Kantor bei St.Michael in Znaim in 1587-1596; 1592 widmete er dem Stadtrat seine Motteten über Christi Geburt, siehe SOkA Znojmo, AMZ, Zahlungsbuch, Sign. AMZ-II 253, Fol. 588 r (11. Jan. 1592: dem Benedicto Lelkowio Cantoris bey S: Michaelis wegen verehrete Moteten von der geburt Jesu Christi gegeben $1 \mathrm{fl}$.); es ist höchstwahrscheinlich, dass sich auch zwei Widmungen vom Oktober und November des vergangegen Jahres seiner Persönlichkeit betreffen, siehe SOkA Znojmo, AMZ, Zahlungsbuch, Sign. AMZ-II 253, Fol. 553r (19. Octob. 1591: Einem Componisten wegen dedicirte Stück Qui confidunt in domino gegeben 1 fl.); ebenda, Fol. 555v (23. Nov. 1591: einem Studioso und Componiste bey der Schull S. Michaelis verehret für etlicher Christlicher Stück 1 fl.). 72 SOkA Olomouc, AMO, I C I a Stadtrechnungsbuch (1611-1630), Sign. 71, Fol. 99r (den 28. Augusti 1615: Abraham Nimphaeo Cantori apud D. Mauritium weg dedicierung eines Officii mit 24 Stim 6 fl.); ibid., Fol. $123 \mathrm{v}$ (den 26. Augusti 1616: Abraham Nimphaeo Cantori zu S. Mauriz wegen dedicirung Te Deum laudamus bey verneuerung des Raths 5 fl.); ibid., Fol. 225v (den 11. Septembris 1620: Abraham Ninffeo wegen dedicirung dem Rath ettlicher muteten 3 fl.). 
Nymphaeus stammt vielleicht aus Oppeln (Oberschlesien, heute Polen), war wahrscheinlich als Organist im Olmützer Dom tätig und später wirkte ca. im Jahren 1614-1619 als Kantor bei St. Mauritz in Olmütz; ${ }^{73}$ er starb im Jahre 1622 in Olmütz. ${ }^{74}$

\section{Die dritte Gruppe - anonyme oder unbekannten Musikalien}

Die letzte Gruppe stellen Widmungen der Autoren dar, deren Namen nicht angeführt wurden. Ohne eine ausführlichere Beschreibung ist in Brünner Rechnungsbüchern im November 1609 ein Eintrag über eine Zahlung an einen Komponisten von Motetten zu finden. ${ }^{75}$ Der Versuch, den Komponisten aus Böhmisch Leipa zu identifizieren, der im Januar $16111 \mathrm{fl}$. von Znaimer Stadtrat für eingeschickte lateinische Musikstücke erhalten hatte, scheiterte ebenfalls. ${ }^{76}$ In Brünner Rechnungsbüchern gibt es auch eine ungewöhnlich hohe Belohnung für einen Prager Drucker aus dem Jahre 1616, die immer noch nicht identifiziert wurde. ${ }^{77}$ Ein Jahr später, im Oktober 1617, bezahlten Olmützer Ratsherren dem königlichen Komponisten die Belohnung in der Höhe $1 \mathrm{fl}^{78}$

73 Laut STRAKOVÁ 1981, op. cit., S. 170 und 174; Jiřina Holinková erwähnt paradoxerweise den Nympheaus auf der Liste aller Arbeiter beim St. Mauritz nicht, vergleiche HOLINKOVÁ, Jiřina. Dvě studie z dějin městské školy na Moravě v předbělohorském obdobi. Olomouc: Monse, 2005, S. 189; im Jahre 1614 befindet sich in städtischen Rechnungsbüchern ein Eintrag über Cantor aus Oppeln, siehe SOkA Olomouc, AMO, I C 1 a Stadtrechnungsbuch (1611-1630), Sign. 71, Fol. 60v (den 3. April 1614: einem botten nach Oppeln wegen Cantors zu S. Mauriz sambt Wardt geldt $1 \mathrm{fl}$.); wir können nur vermuten, dass geht es um Abraham Nymphaeus; sein Name erscheint jedoch in städtischen Rechnungsbüchern, mindestens in Jahren 1615, 1616 (siehe vorige Bemerkung) und 1619, siehe SOkA Olomouc, AMO, I C 1 a Stadtrechnungsbuch (1611-1630), Sign. 71, Fol. 209r (25. Octob. 1619: Abraham Nympheo Cantori S. Mauritii 3 fl.); in den letzten Eintrag über Widmung der Motette von Nymphaeus befindet sich aber keine Bemerkung „Cantor“ und im Jahre 1619 befinden sich überdies in Pfarrrechnungsbüchern zu St. Mauritz Einträge über einen neuen Kantor aus Titschein (SOkA Olomouc, FÚ sv. Mořic, Rechnungsbuch Sign. 21, Fol. 5 und 6); wahrscheinlich wirkte Nymphaeus als Kantor bei St. Mauritz in Olmütz nur bis Jahre 1619.

74 In erhaltenen Inventarium der Verlassenschaft aus Jahre 1622 ist Nymphaus bezeichnet als „gewesener Cantor zue S: Moritz, Mittbürger alhier,“ siehe SOkA Olomouc, AMO, II A 2 a Inventarium der Verlassenschaften, Sign. 123, Nr. 60 .

75 AMB, A 1/3, Ratsrechnungen, Ms. 489, Fol. 9v (7. Nov. 1609: einem Musicum weg etliche Muteten verehrt 3 fl. $18 \mathrm{gr}$.); in Frage kommen z. B. zwei Drucke von Nicolaus Zangius aus 1609, näher über seinen Werk MAŇAS 2020.

76 SOkA Znojmo, AMZ, Zahlungsbuch, Sign. AMZ-II 255, Fol. 361r (29. Jan. 1611: Einem Music: von der Leipa daß einem er: Rath etliche Lateinische sachen verehrt geben $1 \mathrm{fl}$.).

77 AMB, A 1/3, Ratsrechnungen, Ms. 501, Fol. 12v (28. Marty 1616: einem buchdrucker von Praag wegen eines Musicalischen buchs so er einem Er. Rath verehrt Entgeg geben $16 f l$.); in Prag wirkte in dieser Zeit die Offizine von Nicolaus Straus; einer von seinen großen Taten, was Musikdrucke angeht, war die Ausgabe der Sammlung Liber I. missarum von dem Hoforganist und Komponist Charles Luython im Jahre 1609 (RISM A/I: L 3119; LL 3119, die zweite Ausgabe folgte 1611. Laut Vladimír Maňas könnte es sich um die Ausgabe an einen Prager Buchdrucker gerade um Nicolaus Straus handeln (belegt ist Korrespondenz zwischen Straus und Brünner Stadtrat im Jahre 1615, siehe Škrabalová, Ivona: Tzv. Červený kopiár̆ města Brna z let 1615-1618: zhodnoceni pisemné produkce za rok 1616. Diplomová práce FF MU Brno 1989, s. 84.); siehe MAŇAS, 2020; es könnte sich hierbei auch um ein Gesangbuch handeln, das um die Jahre 1615/1616 gedruckt wurde, in Erwähnung könnte z. B. Pijsně na sedm Zialmůw Kagicých Swatého Dawida von Bartoloměj Kožlanský (Praha: Pavel Sessius, 1615) oder Pjsničky 


\section{Zusammenfassung}

Vergleicht man alle Widmungen im Zeitraum von 1560 bis 1620, kann man folgende Schlussfolgerungen ziehen: Außer ein paar Ausnahmen in der Form von kleinen Musikstücken lokaler Komponisten, musikalischer Handschrift des Komponisten Johann Wircker und näher unbekannten Musikstücken von Abraham Nymphaues, handelte sich in allen anderen Fällen um gedruckte Musikalien. Die meisten Widmungen stammen aus der Zeitspanne zwischen den Jahren 1588 und 1606. Von den Druckereien wurde am meisten die von Georg Nigrin in Prag vertreten. Hier wurden die Werke von Jacob Handl Gallus, Johann Knöfel und Franciscus Sale gedruckt. Es gibt keine festgelegte Belohnung für eingeschickte Musikalien. Ihre Höhe schwankt je nach der Stadt. Der höchste Betrag ist auf jeden Fall $30 \mathrm{fl}$. für Magnum opus musicum von di Lasso, was von der Stadt Brünn ausbezahlt wurde. Angesichts dieser Forschungsergebnisse liegt die Schlussfolgerung nahe, dass die Widmungen von Musikalien ein wichtiges von weitem nicht ausgeschöpftes Thema darstellen.

Duchownj, o Smrtedlnosti žiwota lidského (Praha: Samuel Adam z Veleslavína, 1615) gezogen werden; für die Konsultation bedanke ich mich beim Herrn Jan Bata.

78 SOkA Olomouc, AMO, I C 1 a Stadtrechnungsbuch (1611-1630), Sign. 71, Fol. 151r (20. Octob. 1617: einem königlichen Musico verehrt 1 fl.); im September 1617, kurz nach seiner Krönung, besuchte der König Ferdinand II. Olmütz; die Ausgabe dem königlichen Musiker hängt bestimmt mit diesem Aufenthalt zusammen; es ist möglich, dass es hier um einen Druck von dem Hoforganisten und Komponisten Giovanni Valentini aus dem Jahre 1617 Missae concertatae geht, RISM A/I: V 89 (für den Hinweis danke ich wieder dem Herrn Bata). 


\begin{tabular}{|c|c|c|c|c|c|c|c|}
\hline 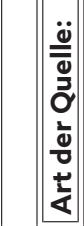 & 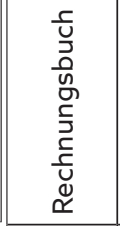 & 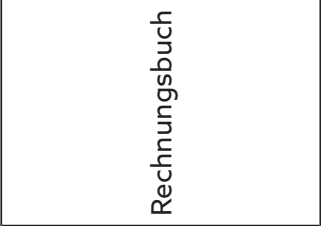 & 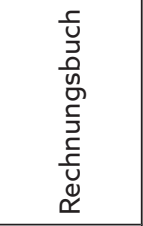 & 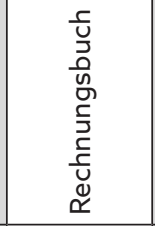 & $\begin{array}{l}\frac{c}{0} \\
\frac{0}{2} \\
\frac{0}{0} \\
\underline{0} \\
\underline{0}\end{array}$ & n. & 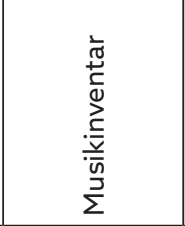 \\
\hline 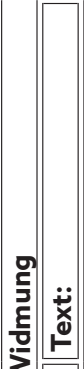 & 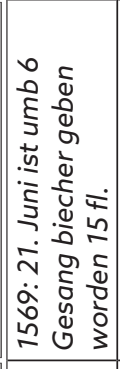 & 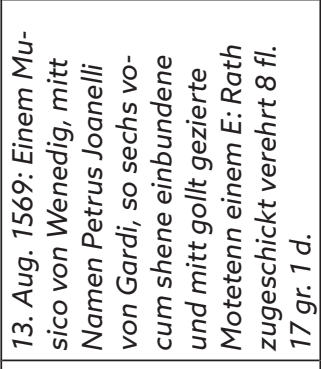 & 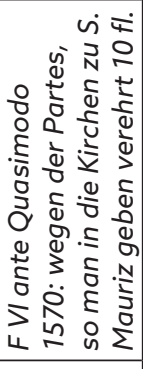 & 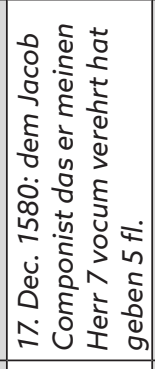 & 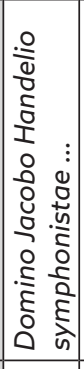 & n. & 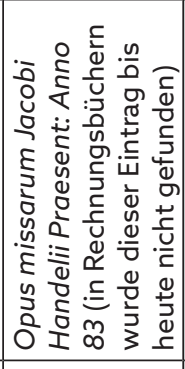 \\
\hline 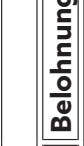 & 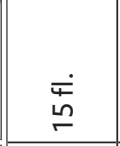 & 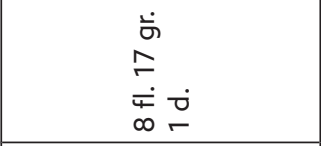 & $\begin{array}{l}\dot{F} \\
\text { 음 }\end{array}$ & 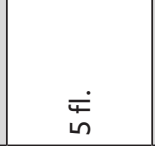 & 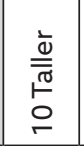 & $\begin{array}{l}\dot{\mp} \\
0\end{array}$ & n. \\
\hline $\begin{array}{l}\dot{i} \\
\tilde{z} \\
\tilde{n} \\
\end{array}$ & : & $\begin{array}{l}\frac{E}{\pi} \\
\stackrel{5}{N} \\
\end{array}$ & $\begin{array}{l}\text { N } \\
: \stackrel{5}{E} \\
\text { O }\end{array}$ & : & 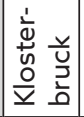 & 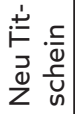 & $\begin{array}{l}\text { N } \\
: \stackrel{5}{E} \\
\text { O }\end{array}$ \\
\hline 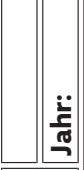 & $\begin{array}{l}a \\
\stackrel{0}{n} \\
\dot{0} \\
\dot{\sim} \\
\dot{\sim}\end{array}$ & $\begin{array}{l}a \\
\infty \\
\stackrel{\circ}{\leftarrow} \\
\infty \\
\dot{m} \\
\dot{m}\end{array}$ & $\begin{array}{l}\text { 을 } \\
\stackrel{n}{n} \\
\dot{m} \\
\dot{m}\end{array}$ & 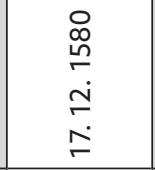 & 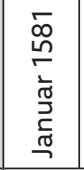 & $\begin{array}{l}\text { N } \\
\text { in } \\
\end{array}$ & $\begin{array}{l}m \\
\infty \\
\stackrel{\infty}{n}\end{array}$ \\
\hline 莒 & \multicolumn{3}{|c|}{$\begin{array}{l}\text { 象 } \\
\text { h้ }\end{array}$} & 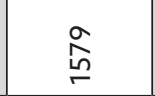 & \multicolumn{3}{|c|}{$\begin{array}{l}\stackrel{\circ}{\infty} \\
\stackrel{n}{n}\end{array}$} \\
\hline 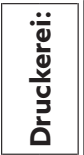 & \multicolumn{3}{|c|}{ 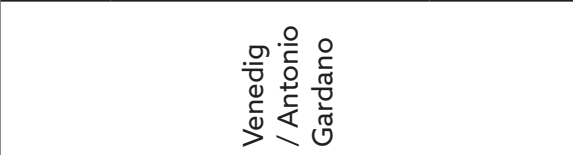 } & 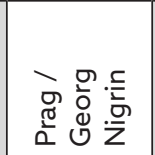 & \multicolumn{3}{|c|}{ 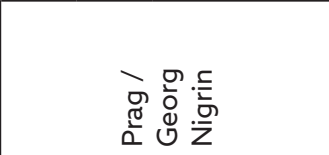 } \\
\hline$\frac{\ddot{\underline{M}}}{\underline{\underline{x}}}$ & \multicolumn{3}{|c|}{ 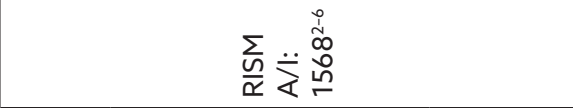 } & $x$ & \multicolumn{3}{|c|}{ 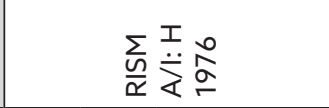 } \\
\hline 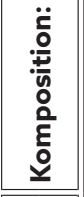 & \multicolumn{3}{|c|}{ 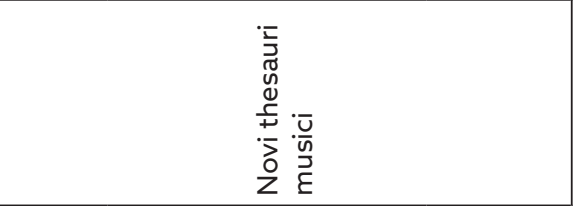 } & 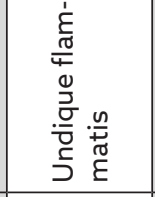 & \multicolumn{3}{|c|}{ 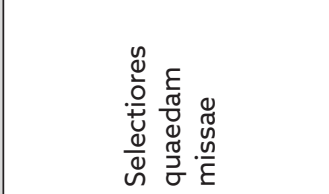 } \\
\hline 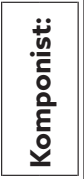 & \multicolumn{3}{|c|}{ 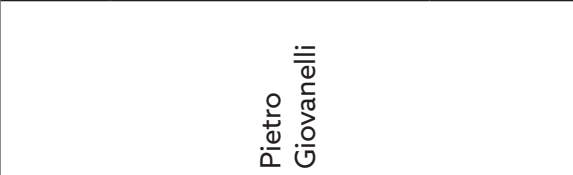 } & 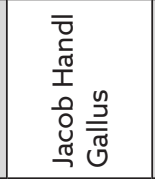 & \multicolumn{3}{|c|}{ 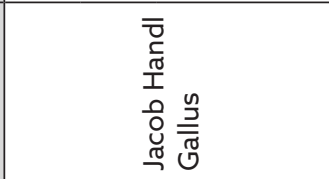 } \\
\hline
\end{tabular}




\begin{tabular}{|c|c|c|c|c|c|c|c|}
\hline 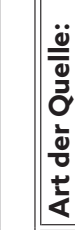 & 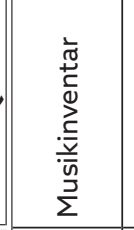 & 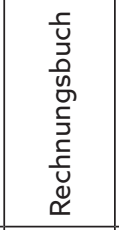 & 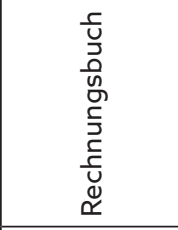 & 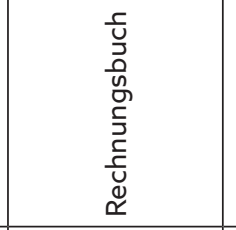 & 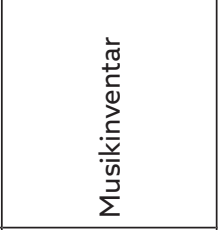 & 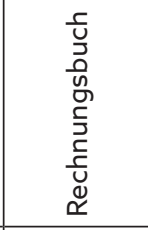 & 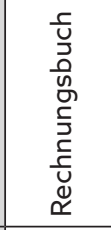 \\
\hline 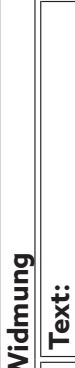 & 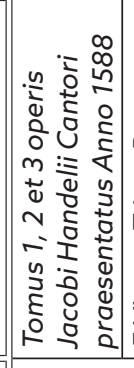 & 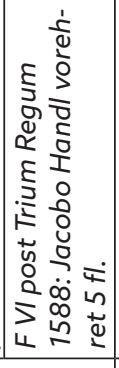 & 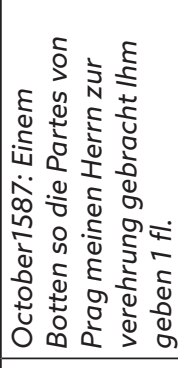 & 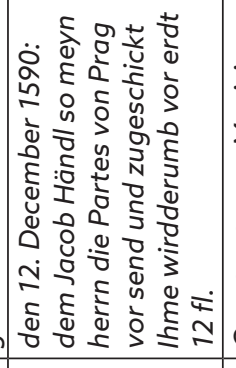 & 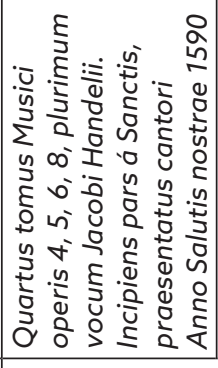 & 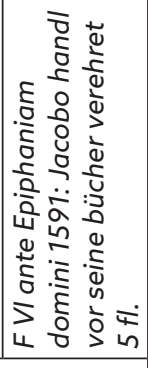 & 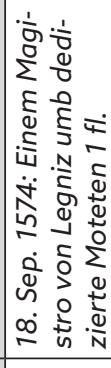 \\
\hline 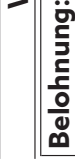 & $\overrightarrow{\dot{t}}$ & $\stackrel{\dot{E}}{\circ}$ & 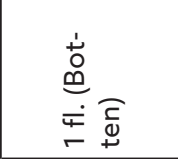 & $\begin{array}{l}\dot{\rightleftarrows} \\
\stackrel{\sim}{\sim}\end{array}$ & $\frac{\dot{F}}{\operatorname{Ln}}$ & & $\underset{r}{\stackrel{\rightleftarrows}{\leftarrow}}$ \\
\hline 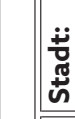 & $\begin{array}{l}N \\
: \\
\text { : } \\
\text { E } \\
0\end{array}$ & 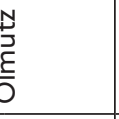 & : & : & $\begin{array}{l}N \\
: \vec{F} \\
\text { E } \\
0\end{array}$ & & $\begin{array}{l}\frac{E}{\pi} \\
\stackrel{N}{N}\end{array}$ \\
\hline 节 & 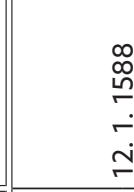 & 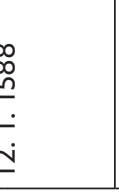 & 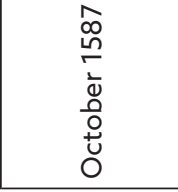 & 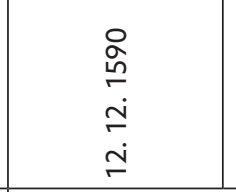 & $\begin{array}{l}\bar{\sigma} \\
\stackrel{5}{\circ} \\
\dot{\sigma} \\
\dot{r}\end{array}$ & & $\begin{array}{l}\frac{1}{n} \\
\stackrel{0}{\infty} \\
\infty \\
\infty\end{array}$ \\
\hline$\frac{\ddot{\check{L}}}{\text { I্ }}$ & \multicolumn{3}{|c|}{ 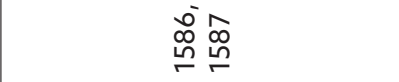 } & \multicolumn{3}{|c|}{ 옹 } & $\stackrel{5}{n}$ \\
\hline 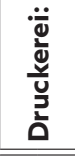 & \multicolumn{3}{|c|}{ 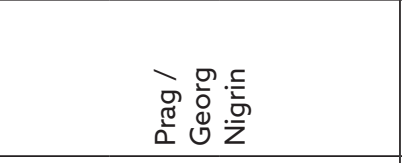 } & \multicolumn{3}{|c|}{ 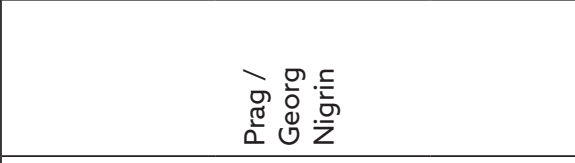 } & 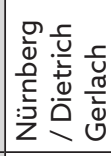 \\
\hline$\frac{\ddot{n}}{\frac{\underline{n}}{\alpha}}$ & \multicolumn{3}{|c|}{ 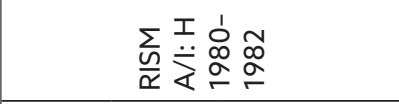 } & \multicolumn{3}{|c|}{ 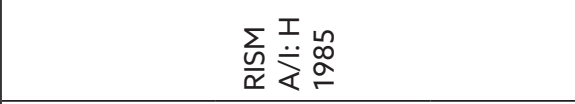 } & 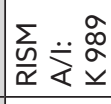 \\
\hline 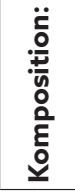 & \multicolumn{3}{|c|}{ 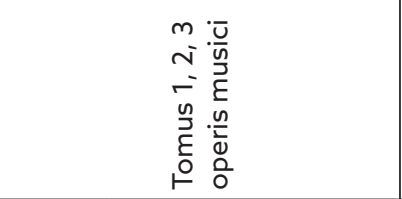 } & \multicolumn{3}{|c|}{ 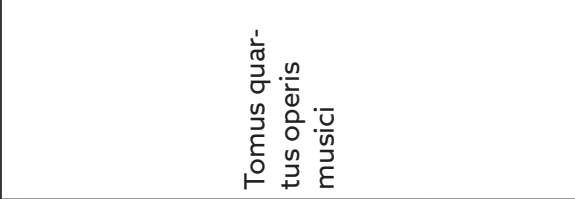 } & 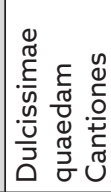 \\
\hline 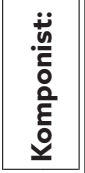 & \multicolumn{3}{|c|}{ 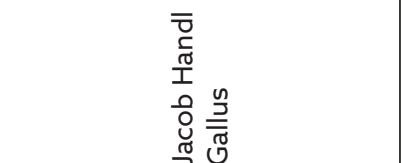 } & \multicolumn{3}{|c|}{ 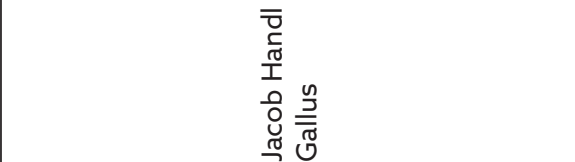 } & 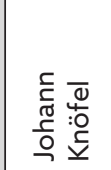 \\
\hline
\end{tabular}




\begin{tabular}{|c|c|c|c|c|c|c|}
\hline 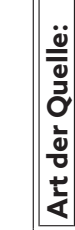 & 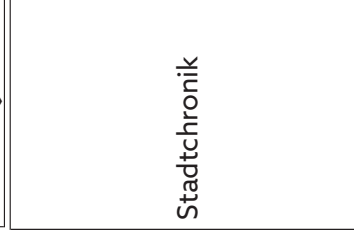 & 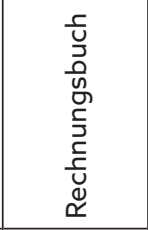 & 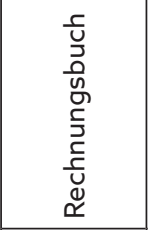 & 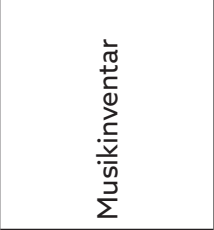 & 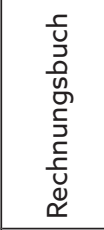 & 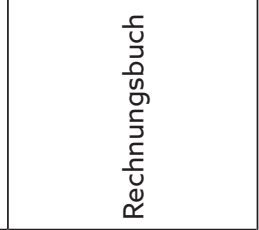 \\
\hline |ே.| & 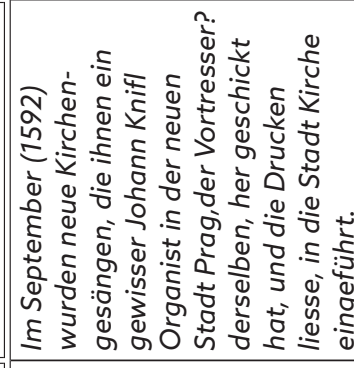 & 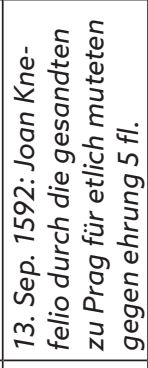 & 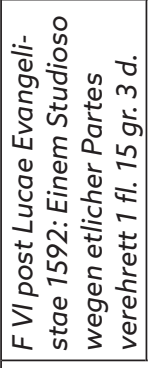 & 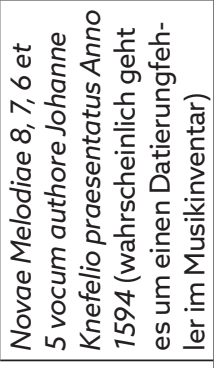 & 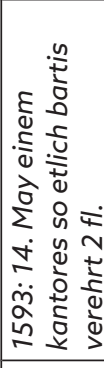 & 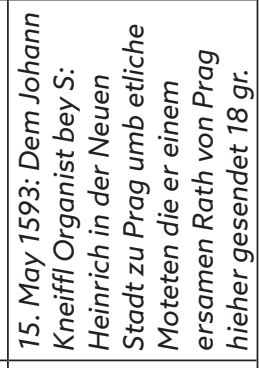 \\
\hline 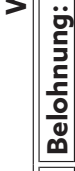 & a. & 店 & & 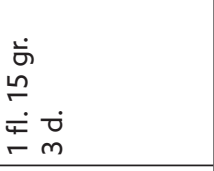 & 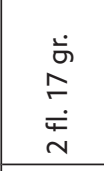 & $\begin{array}{l}\text { 汖 } \\
\infty \\
\end{array}$ \\
\hline $\begin{array}{l}\text { in } \\
\mathbf{f} \\
\text { ஸे } \\
\end{array}$ & 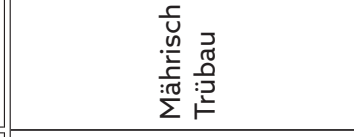 & 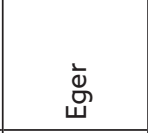 & & $\begin{array}{l}N \\
: ~ \\
E \\
\text { E } \\
0\end{array}$ & 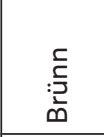 & $\begin{array}{l}\frac{E}{\pi} \\
\stackrel{N}{N}\end{array}$ \\
\hline 苟 & 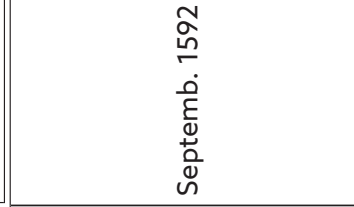 & 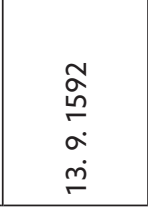 & & 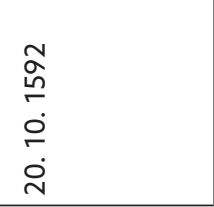 & $\begin{array}{l}m \\
\stackrel{m}{\leftarrow} \\
\dot{n} \\
\dot{j} \\
\dot{+}\end{array}$ & $\begin{array}{l}m \\
\stackrel{0}{n} \\
\text { in } \\
\stackrel{n}{n}\end{array}$ \\
\hline 莒 & \multicolumn{5}{|c|}{ 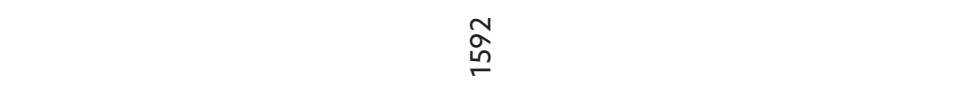 } & \\
\hline 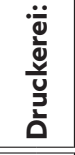 & \multicolumn{6}{|c|}{ 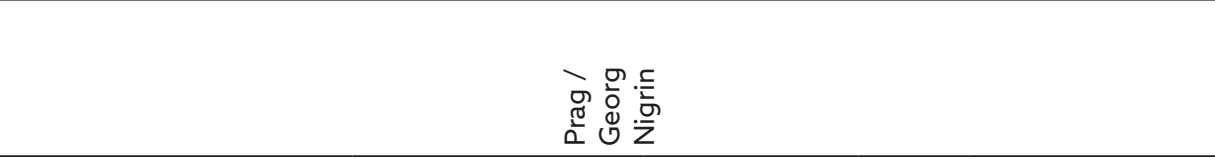 } \\
\hline$\frac{\ddot{\underline{n}}}{\underline{\underline{\alpha}}}$ & \multicolumn{6}{|c|}{ 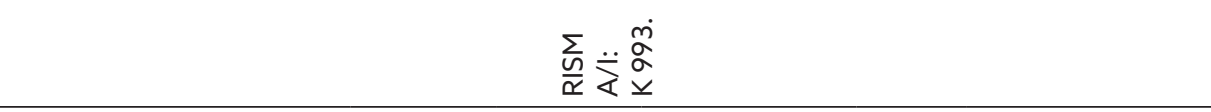 } \\
\hline 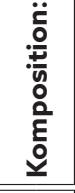 & \multicolumn{6}{|c|}{ 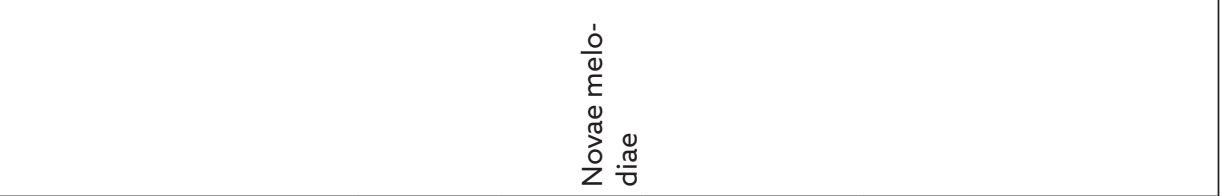 } \\
\hline 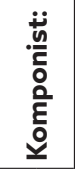 & \multicolumn{6}{|c|}{ 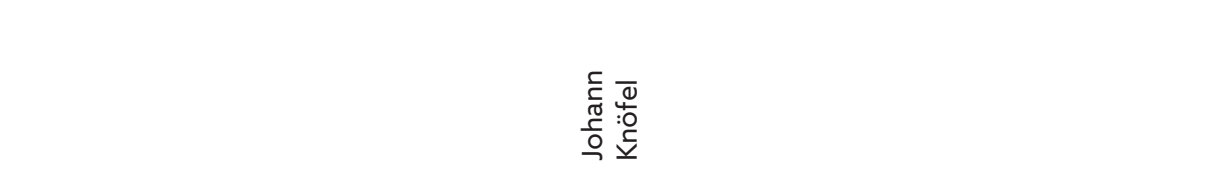 } \\
\hline
\end{tabular}




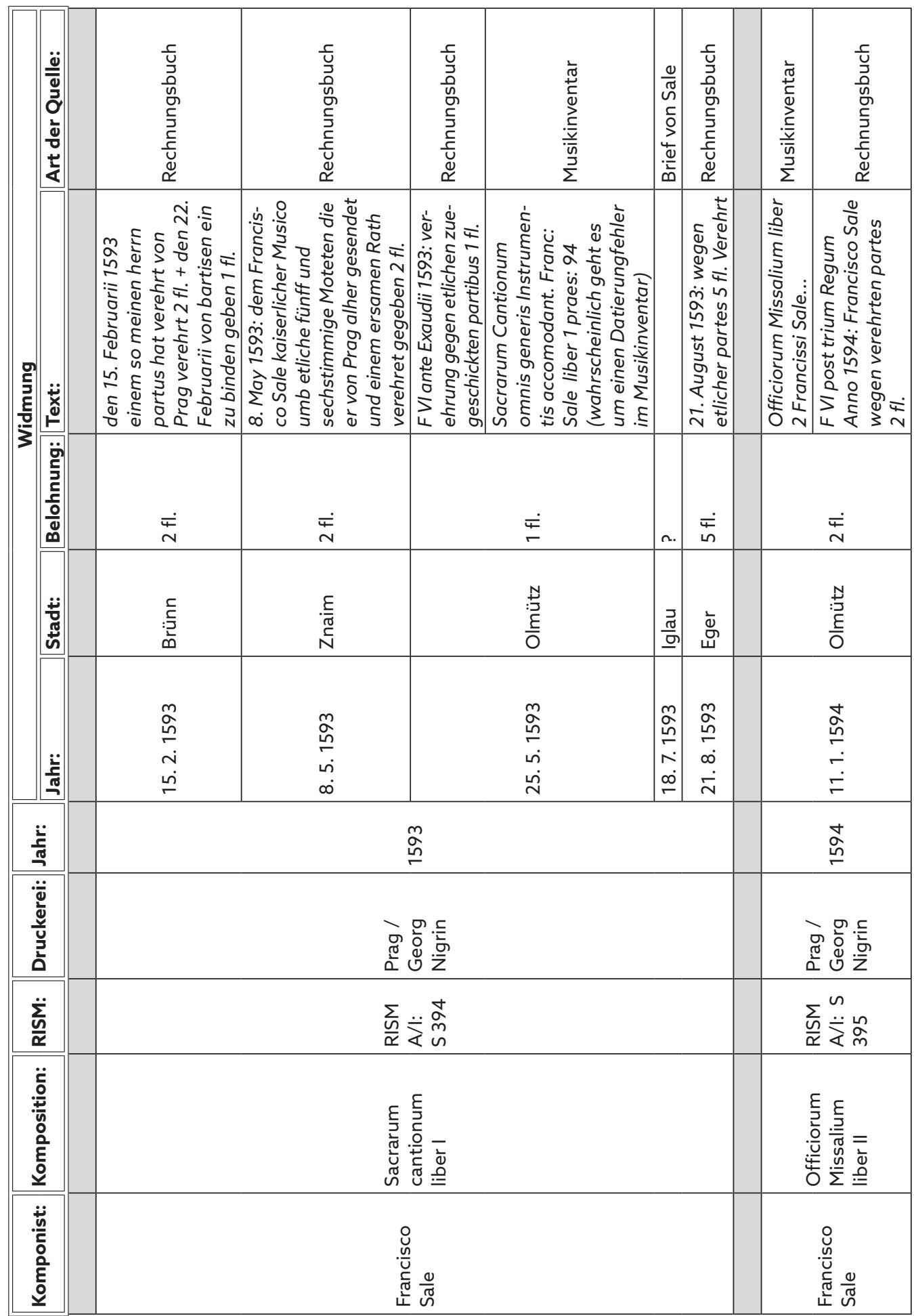




\begin{tabular}{|c|c|c|c|c|c|c|}
\hline 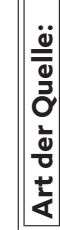 & 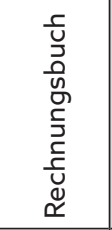 & 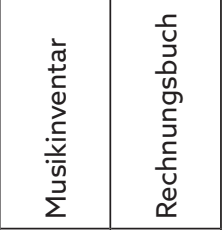 & 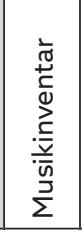 & 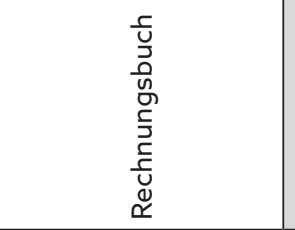 & 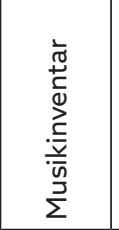 & 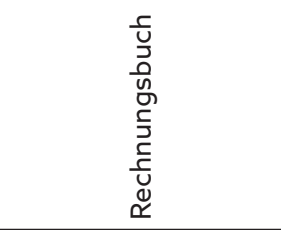 \\
\hline 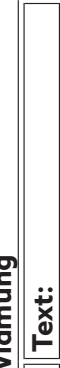 & 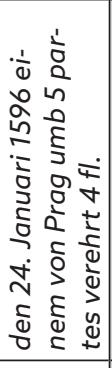 & 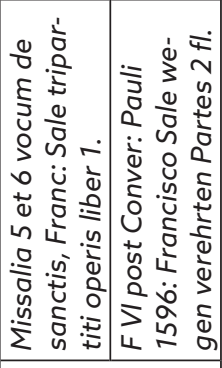 & 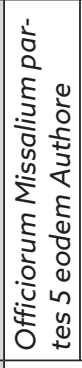 & 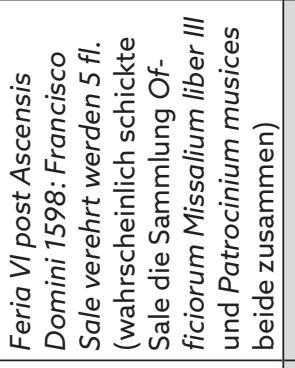 & 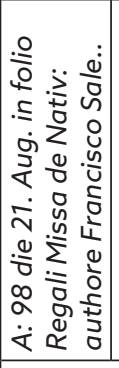 & 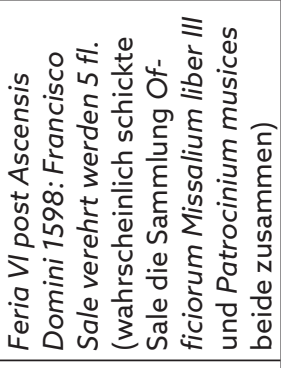 \\
\hline 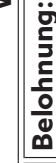 & $\underset{+}{\dot{+}}$ & $\stackrel{\dot{\leftarrow}}{\sim}$ & & 㠵 & & $\underset{\text { in }}{\dot{E}}$ \\
\hline 泀 & 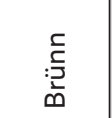 & $\begin{array}{l}\text { N } \\
\stackrel{\tilde{z}}{\xi} \\
0\end{array}$ & & $\begin{array}{l}\text { 节 } \\
\text { E् }\end{array}$ & & 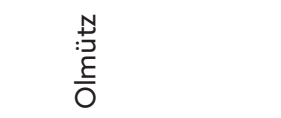 \\
\hline 竞 & 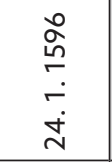 & 。̊ & & $\begin{array}{l}\text { o } \\
\stackrel{0}{\omega} \\
\text { in } \\
\dot{0} \\
\dot{0}\end{array}$ & & 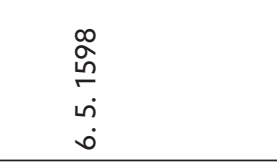 \\
\hline 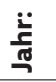 & & مْ & & 움 & & 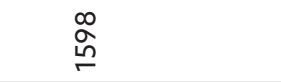 \\
\hline 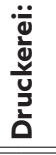 & & 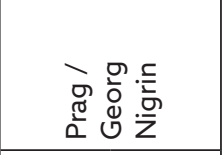 & & 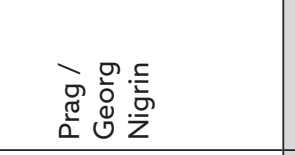 & & 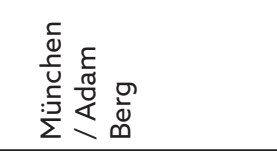 \\
\hline$\frac{\sum_{\frac{M}{\alpha}}}{\underline{x}}$ & & 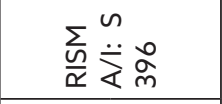 & & $\sum_{\frac{i}{\alpha}}^{n} \ddot{\bar{\psi}} \hat{i}$ & & 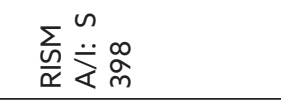 \\
\hline 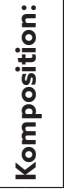 & & 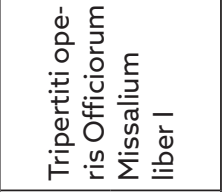 & & 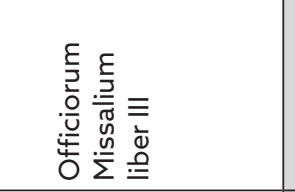 & & 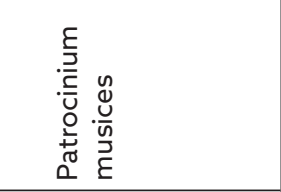 \\
\hline 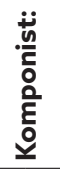 & & 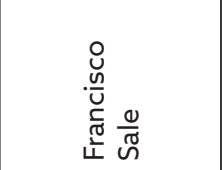 & & 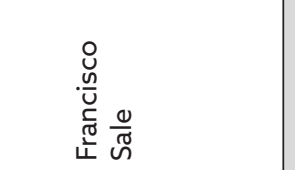 & & 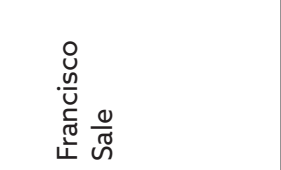 \\
\hline
\end{tabular}




\begin{tabular}{|c|c|c|c|c|c|c|c|}
\hline 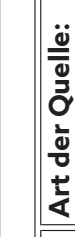 & 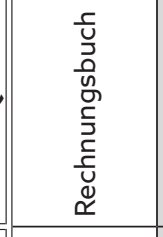 & 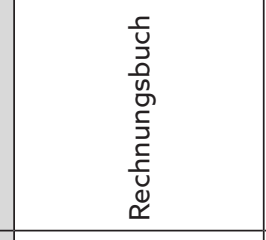 & 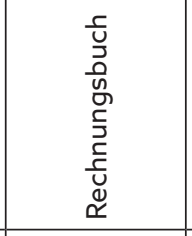 & 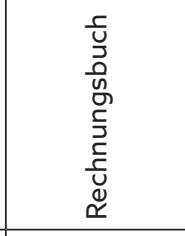 & 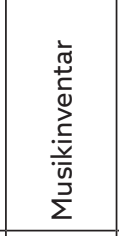 & 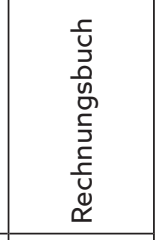 & 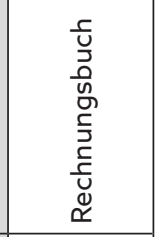 \\
\hline 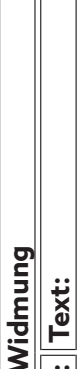 & 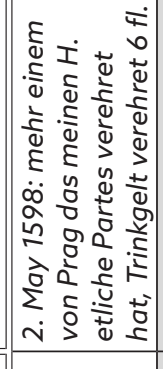 & 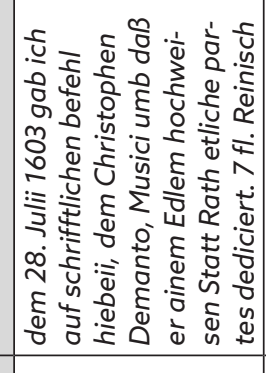 & 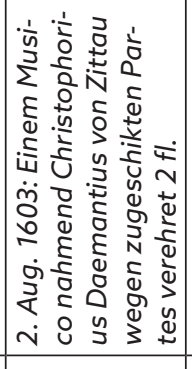 & 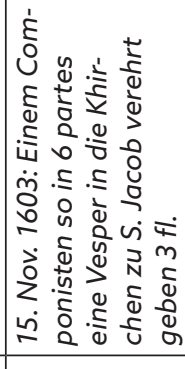 & 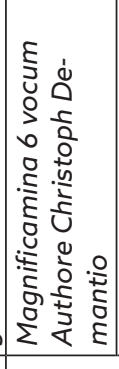 & 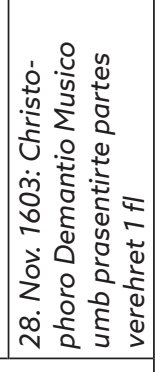 & 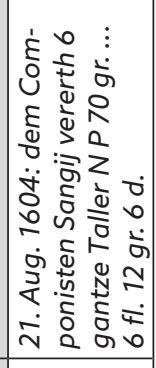 \\
\hline 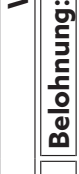 & $\begin{array}{l}\dot{+} \\
0\end{array}$ & $\stackrel{\dot{T}}{\wedge}$ & $\stackrel{\dot{4}}{\sim}$ & $\begin{array}{l}\dot{\leftarrow} \\
m\end{array}$ & & $\begin{array}{l}\dot{+} \\
-\end{array}$ & 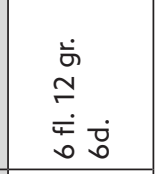 \\
\hline 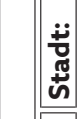 & 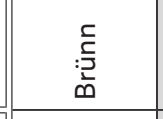 & $\sum_{\bar{j}}^{\bar{\omega}}$ & $\begin{array}{l}\frac{E}{\pi} \\
\text { N } \\
\end{array}$ & 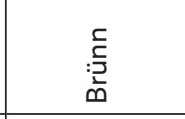 & & $\begin{array}{l}N \\
: \overrightarrow{7} \\
\text { E⿱ } \\
0\end{array}$ & 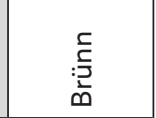 \\
\hline 泀 & $\begin{array}{l}\text { o } \\
\stackrel{0}{n} \\
i \\
i \\
i \\
i\end{array}$ & $\begin{array}{l}0 \\
0 \\
\stackrel{0}{r} \\
\infty \\
\stackrel{0}{N}\end{array}$ & $\begin{array}{l}m \\
0 \\
0 \\
\infty \\
\infty \\
i \\
i\end{array}$ & $\begin{array}{l}m \\
0 \\
\dot{0} \\
\dot{+} \\
\dot{+} \\
\dot{n}\end{array}$ & & 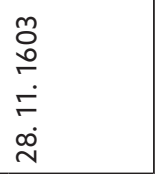 & $\begin{array}{l}\dot{0} \\
\circ \\
\infty \\
\infty \\
\dot{N}\end{array}$ \\
\hline 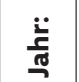 & & \multicolumn{5}{|c|}{$\begin{array}{l}\text { రิ } \\
\text { రి }\end{array}$} & $\begin{array}{l}m \\
0 \\
0\end{array}$ \\
\hline 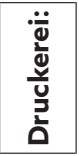 & & \multicolumn{5}{|c|}{ 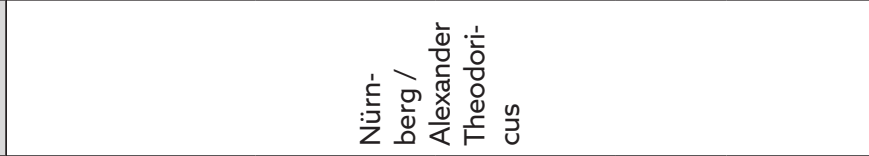 } & 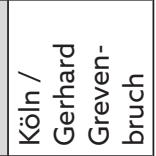 \\
\hline$\frac{\ddot{\Sigma}}{\underline{\underline{w}}}$ & & \multicolumn{5}{|c|}{ 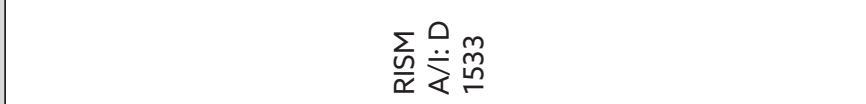 } & $\sum_{\frac{N}{\alpha}}^{N}$ \\
\hline 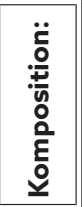 & & \multicolumn{5}{|c|}{ 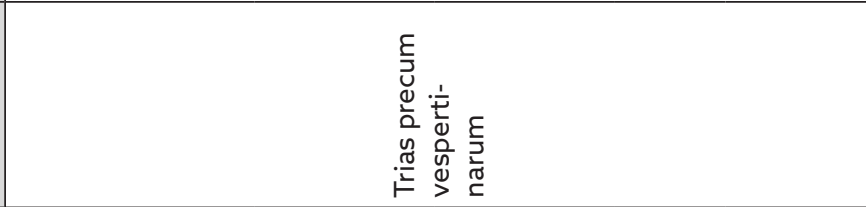 } & 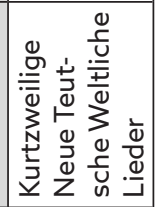 \\
\hline 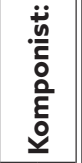 & & \multicolumn{5}{|c|}{ 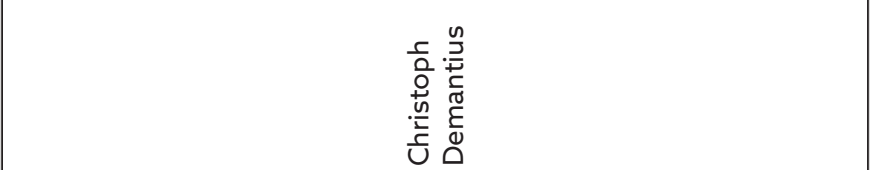 } & 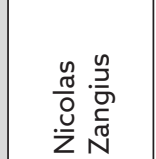 \\
\hline
\end{tabular}




\begin{tabular}{|c|c|c|c|c|c|c|}
\hline 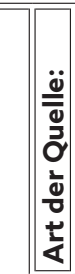 & 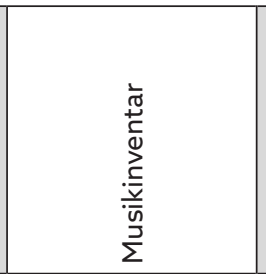 & 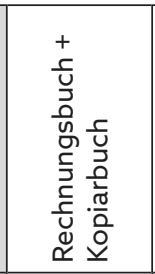 & 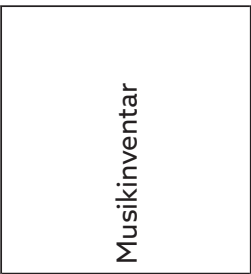 & 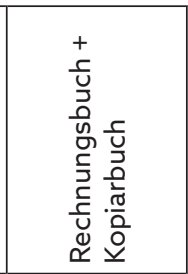 & 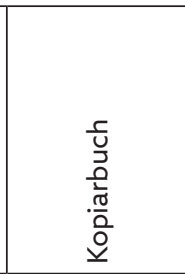 & 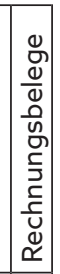 \\
\hline 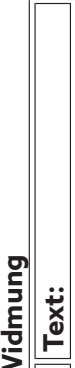 & 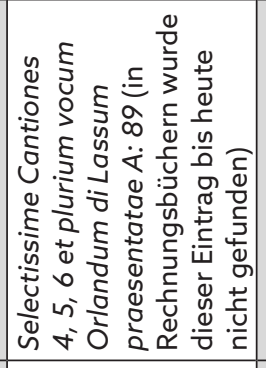 & 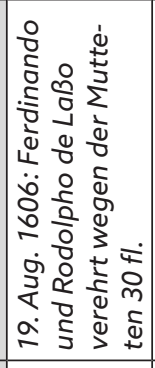 & 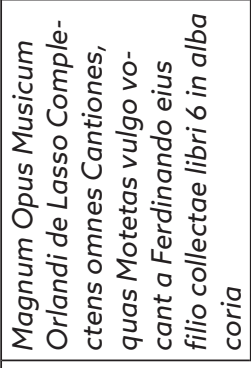 & 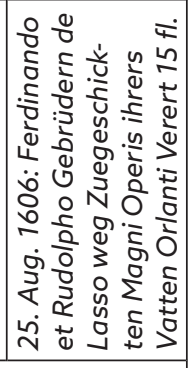 & 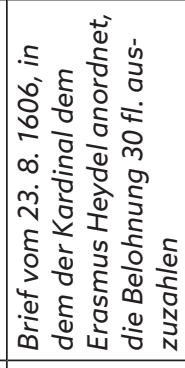 & . \\
\hline 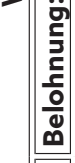 & a. & $\begin{array}{l}\dot{4} \\
0 \\
0\end{array}$ & $\begin{array}{l}\dot{T} \\
\stackrel{\dot{m}}{r} \\
\end{array}$ & & $\begin{array}{l}\dot{N} \\
\stackrel{m}{m}\end{array}$ & $\begin{array}{l}\dot{F} \\
\stackrel{\dot{m}}{ \pm}\end{array}$ \\
\hline 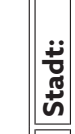 & 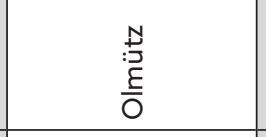 & : & 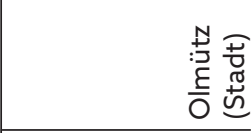 & & 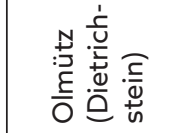 & 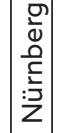 \\
\hline 节 & $\begin{array}{l}\stackrel{\infty}{\infty} \\
\stackrel{\leftrightarrow}{\circ}\end{array}$ & $\begin{array}{l}\circ \\
0 \\
\leftarrow \\
\infty \\
0 \\
\sigma\end{array}$ & $\begin{array}{l}\stackrel{0}{0} \\
\circ \\
\infty \\
\stackrel{0}{n} \\
\stackrel{n}{~}\end{array}$ & & $\begin{array}{l}\stackrel{0}{0} \\
\leftarrow \\
\infty \\
\ddot{N} \\
\ddot{N}\end{array}$ & \begin{tabular}{c|}
$n$ \\
0 \\
0 \\
$\infty$ \\
$\infty$ \\
$\infty$ \\
$\infty$ \\
\end{tabular} \\
\hline 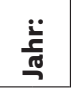 & $\begin{array}{l}\stackrel{\infty}{\infty} \\
\stackrel{n}{n}\end{array}$ & \multicolumn{5}{|c|}{\begin{tabular}{l}
0 \\
0 \\
\hdashline
\end{tabular}} \\
\hline 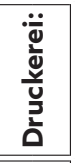 & 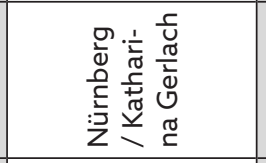 & \multicolumn{5}{|c|}{ 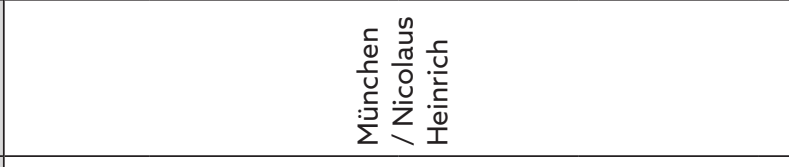 } \\
\hline$\frac{\ddot{\Sigma}}{\frac{\underline{n}}{\alpha}}$ & 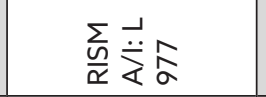 & \multicolumn{5}{|c|}{ 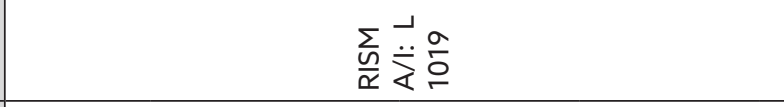 } \\
\hline 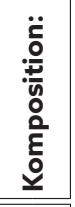 & 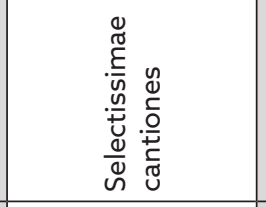 & \multicolumn{5}{|c|}{ 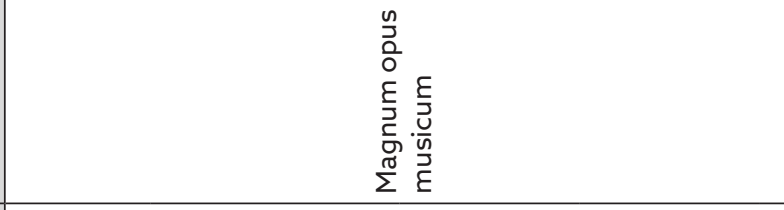 } \\
\hline 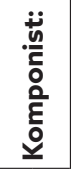 & 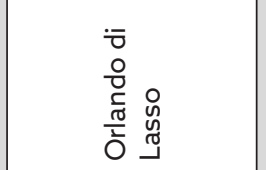 & \multicolumn{5}{|c|}{ 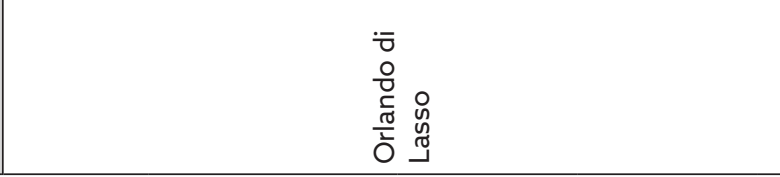 } \\
\hline
\end{tabular}




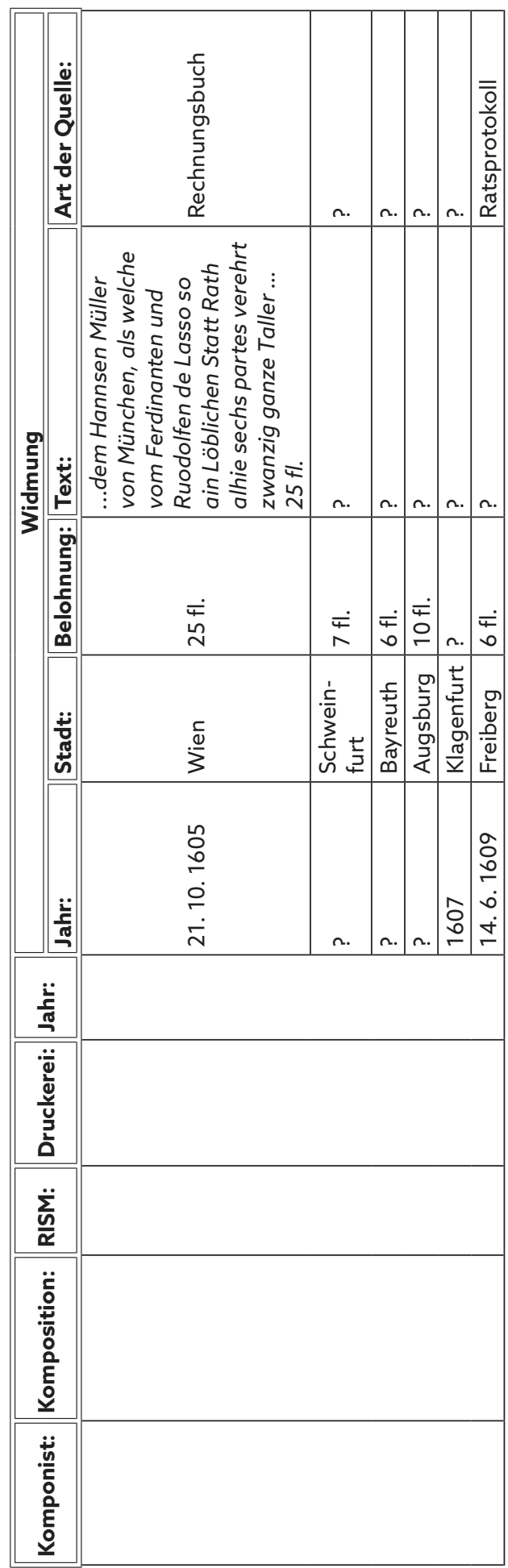




\section{Bibliography}

BECK, Josef. Geschichte der Stadt Neutitschein und deren Umgebung. Neutitschein: Schnellpressendruck von J. R. Enders, 1854.

BOETTICHER, Wolfgang. Orlando di Lasso und seine Zeit 1532-1594: Repertoire - Untersuchungen zur Musik der Spätrenaissance: mit 317 Notenbeispielen. Bd. 1, Monografie. Kassel: BärenreiterVerlag, 1958.

ČAPSKÁ, Veronika. Výzkum raně novověké směny darů a prameny osobní povahy - k možnostem antropologizace ekonomických dějin střední Evropy. In Dějiny - teorie - kritika, Jg. 14, Nr. 2, Praha: Fakulta humanitních studií UK, 2017, S. 191-225.

DANĚK, Petr - BAŤA, Jan. Numero Arithmetico notata Series officiorum pro Choro Ustensi (1588) aneb pramen polyfonie plný překvapení. Musicologica Istropolitana, Jg. 2011-2012, Nr. X-XI, S. 45-67.

DANĚK, Petr. Historické tisky vokálni polyfonie, rané monodie, hudebni teorie a instrumentálni hudby $v$ českých zemích do roku 1630: se soupisem tisků z let 1488-1628 uložených v Čechách. Praha: KLP, 2015.

EITNER, Robert. Wircker, Johann. In Biographisch-bibliographisches Quellen-Lexikon. Band 9. Graz: Akademische Druck- und Verlagsanstalt, 1959, S. 279.

FEDERHOFER, Hellmut. Italienische Musik am Hofe des Fürstbischofs von Gurk, Johann Jakub von Lamberg (1603-1630). In OLSCHKI, Leo S. Collectanea Historiae Musicae. II. Florentiae: Leonis S. Olschki, 1956, S. 163-168.

FEDERHOFER, Hellmut. Musikpflege und Musiker am Grazer Habsburgerhof der Erzherzöge Karl und Ferdinand von Innerösterreich: 1564-1619. Mainz: B. Schott's Söhne, 1967.

GALLUS-HANDL, Jacob. Undique flammatis, Epicedion harmonicum. In DESMET, Marc - MOTNIK, Marko - GRABNAR, Klemen (eds.). Monumenta artis musicae Sloveniae. Ljubljana: Slovenska Akademija Znanosti in Umetnosti, 2015.

HOLINKOVÁ, Jiřina. Dvě studie z dějin městské školy na Moravě v predbělohorském obdobi. Olomouc: Monse, 2005.

HORYNA, Martin - MAŇAS, Vladimír. Two Manuscripts of Polyphonic Music in Brno from the Mid-Sixteenth Century. Early Music 40, 2012, Nr. 4, S. 553-575.

CHARTERIS, Richard. Newly discovered music manuscripts from the private collection of Emil Bohn. American Institute of Musicology, Holzgerlingen: Hänssler Verlag, 1999.

KAPSA, Václav - MAŇAS, Vladimír - SPÁČILOVÁ, Jana. Hudební inventáre raného novověku v českých zemich (im Druck).

KOPPITZ, Hans Joachim (ed.). Die kaiserlichen Druckprivilegien im Haus-, Hof- und Staatsarchiv Wien: Verzeichnis der Akten vom Anfang des 16. Jahrhunderts bis zum Ende des Deutschen Reichs (1806). Wiesbaden: Otto Harrassowitz Verlag, 2008.

LESZCZYŃSKA, Agnieszka. Music and Musicians in Late-Renaissance Toruń. In KRASSOWSKI, Janusz (ed.). Musica Baltica: the music culture of Baltic cities in modern times. Gdańsk: Akademia Muzyczna im. Stanisława Moniuszki, Gdańsk, 2010. Prace specjalne, S. 165-175.

LESZCZYŃSKA, Agnieszka. W poszukiwaniu hanzeatyckiego sponsora: listy muzyków z przelomu XVI i XVII wieku do rad miejskich Torunia i Gdańsk. In JEŻ, Tomasz (ed.). Complexus effectuum musicologiae; studia Miroslao Perz septuagenario dedicate. Wydanie I. Kraków: Rapid, 2003, S. 239-247.

LEWIS HAMMOND, Susan. Editing music in early modern Germany. London: Routledge, 2016.

MAŇAS, Vladimír. Inventář hudebnin farního kostela v Novém Jičíně z roku 1630. Musicologica Brunensia, 2012, Jg. 47, Nr. 2, S. 73-77. 
MAŇAS, Vladimír. Rukopisy renesanční polyfonie - zapomenutá a přitom cenná součást svatojakubské farní knihovny. In Brno v minulosti a dnes: př́spěvky $k$ dějinám a výstavbě Brna. Brno: Statutární město Brno, Archiv města Brna, 2013, Nr. 26, S. 39-49.

MAŇAS, Vladimír. Nicolaus Zangius: hudebnik prélomu 16. a 17. století. Na stopě neznámému. Brno: Masarykova univerzita, 2020.

MAŇAS, Vladimír. Rudolfínská Morava (im Druck).

MOTNIK, Marko. Jacob Handl-Gallus: Werk - Überlieferung - Rezeption; Mit thematischem Katalog. Tutzing: Verlegt bei Hans Schneider, 2012.

RIESS, Karl. Musigeschichte der Stadt Eger im 16. Jahrhundert. Brünn: Rudolf M. Rohrer, 1935.

ROSE, Stephen. The Mechanisms of the Music Trade in Central Germany, 1600-40. Journal of the Royal Musical Association, Vol. 130, N. 1 (2005), S. 1-37.

SEHNAL, Jiří. Hudba na dvoře olomouckých biskupů od 13. do poloviny 17. století. Časopis vlasteneckého spolku musejniho v Olomouci, Nr. 60, 1970, S. 73-86.

SEHNAL, Jiří. Hudba v magistrátních účtech Brna do konce třicetileté války. In Historická Olomouc a jeji současné problémy IV. Olomouc: Palacký-Universität, 1983, S. 335-343.

SEHNAL, Jiří. Die Musik in Mähren gegen Ende des 16. Jahrhunderts und Jacobus Gallus. In Gallus Carniolus in Evropska Renesansa 1. Ljubljana: Slovenska akademija znanosti in umetnosti, 1991, S. 33-43.

SEHNAL, Jiří. Hudební inventář kostela v Moravské Třebové z konce třicetileté války. Hudebni věda, 2015, Jg. 52, Nr. 1, S. 5-28.

SCHRAM, Wilhelm. Der Abt von Kloster-Bruck Freitag v. Cziepiroh (1573-1585). Zeitschrift des Vereines für die Geschichte Mährens und Schlesiens, 3, 1899, S. 312-324.

STRAKOVÁ, Theodora. Vokálně polyfonní skladby na Moravě v 16. a na počátku 17. století. 1: Př́ispěvek k poznání hudebního života na Moravě v době předbělohorské. Časopis Moravského muzea: vědy společenské, 1981, Nr. 66, S. 165-178; 2: Jakob Hand-Gallus v českých zemích. Časopis Morauského muzea: vědy společenské, 1982, Nr. 67, S. 85-95.

STUDENIČOVÁ, Hana. Q. In Search of musicalia from the Baroque Library of the Augustinian Eremites in Brno. Musicologica Brunensia, 2018, Jg. 53, Nr. 2, S. 5-23.

STUDENIČOVÁ, Hana: Městská hudebni kultura na Moravě v předbělohorském obdobi. Moravská královská města ve středoevropských souvislostech. Dissertation. Brno: Masaryk-Universität, 2019.

STUDENIČOVÁ, Hana. Moravská královská města, Bratislava a Vídeň: shody a odlišnosti v městském hudebním prostředí v 16. a na počátku 17. století. Musicologica Slovaca 2019, Jg. 10, Nr. 2, S. 177-216.

ŠEBESTA, Josef. Mecenášství renesančních Habsburků? Miscellanea z výročni konference České společnosti pro hudebni vědu 2008, Praha 2010, S. 25-30.

WEINHOLD, Liesbeth. Wircker, Johann. In SADIE, Stanley - TYRRELL, John (eds.). The New Grove Dictionary of Music and Musicians. 2nd ed. New York: Grove, 2001, S. 445.

WILLIAMSON, Magnus. The Fate of Choirbooks in Protestant Europe. Journal of the Alamire Foundation, 2015, Vol. 7, N. 2, S. 117-131.

ZAVARSKÝ, Ernest. Príspevok k dejinám hudby v Kremnici I. Hudobný archív, Jg. 1977, Nr. 2, S. 9-121. 
